\title{
Patentes y crecimiento económico, el caso de México durante el TLCAN*
}

\section{Patents and Economic Growth, the case of Mexico during the NAFTA}

\author{
Alenka Guzmán, ** Hortensia Gómez Viquez*** \\ y Francisco López Herrera****
}

\section{RESUMEN}

Tras caracterizar la naturaleza de las patentes concedidas en México por el Instituto Mexicano de la Propiedad Intelectual (IMPI), el objetivo de este artículo es examinar la relación entre el número de patentes de residentes y el crecimiento económico durante 1991-2015. En una tendencia creciente de dependencia tecnológica en México, los hallazgos con base en un modelo de cointegración de patentes y crecimiento económico de largo plazo y un modelo vectorial de corrección del error, sugieren que el cambio marginal en las patentes afecta la tasa de crecimiento del PIB, pero éste no tiene un efecto significativo en el cambio en el número de las patentes $-\triangle P A T_{I}-$. Además, se aprecia la probable presencia de un cambio estructural. Finalmente, se detecta que los shocks en el número de patentes y en el crecimiento del PIB tienen sólo efectos transitorios en el $\Delta$ pat $_{i}$, pero el shock en éste tiene efectos en el $\Delta$ PIB probablemente sustancialmente negativos y permanentes.

Palabras clave: Innovación, patentes y crecimiento económico, causalidad Granger cointegración, México, TLCAN.

Clasificación JEL: O43, O16, E44

\begin{abstract}
Once characterized the nature of patents granted in Mexico by the Instituto Mexicano de la Propiedad Intelectual (IMPI), the aim of this paper is to analyze the long-run relationship between economic activity and the number of resident holders patents during the period 1991-2015. Within the context of a growing Mexican technological dependence, the findings based on an econometric cointegrating model between such variables and a Vector Error Correction Model (VECM), suggest that the marginal change in the patents affects the GDP growth rate but this does not have a significant effect on the number of patents change. Also, it is possible to appreciate a structural change. Finally, we detect that shocks in both, the number of patents and GDP have only transient effects on the number of patents, but the shocks in the number of patents have effects on PIB that could be significantly negative and permanent.
\end{abstract}

Key words: Innovation, patents and economic growth, cointegration Granger causality, Mexico, IMPI, NAFTA. JEL Classification: O43, O16, E44

*Fecha de recepción: 28/02/2018. Fecha aprobación: 21/06/2018.

**Universidad Autónoma Metropolitana Iztapalapa. Correo: alenka.uami@gmail.com. orCID: 0000-002-7227-4233

***Instituto Politécnico Nacional. Correo: hgomezviquez@yahoo.com.mx. oRCID: 0000-0002$1820-1877$

****Universidad Nacional Autónoma de México. Correo: franciscolopezherrera@yahoo.com.mx. ORCID: 0000-0003-2626-9246 
178 ECONOMÍA TeORía y PRÁCTICA • Nueva Época, Número especial, vol. 4, agosto 2018

\section{INTRODUCCIÓN}

En la coyuntura actual se ha cuestionado la pertinencia de mantener, negociar o concluir el Tratado de Libre Comercio de América del Norte (TLCAN, NAFTA, por sus siglas en inglés). Desde la visión del nuevo gobierno de Estados Unidos, este país mantiene importantes desventajas que lo llevan a registrar un déficit comercial frente a México. Sin embargo, los balances no sólo pueden reducirse a estudiar el desempeño comercial con ese único indicador, sino habría que analizar aspectos como aquel relativo al pago de regalías y pagos por licencias, patentes, marcas, así también por derechos de autor, en el marco de los flujos comerciales. Si bien es cierto que el TLCAN estaba orientado a la negociación comercial de bienes y servicios, un aspecto que devino central en éste fue el comercio de tecnología y los flujos de capital de conocimiento (Park, 2011). En tal medida, el análisis de las patentes adquiere relevancia porque es un indicador del que se puede disponer información de manera sistemática y revela cuáles son los titulares residentes y no residentes dinámicos en las novedades tecnológicas y su probable escalamiento industrial y comercial (Grilliches, 1990; Scherer, 1999). Si el estudio del desempeño tecnológico y de innovación se vincula al desarrollo económico y social alcanzado por los tres países de la región se podrá contar, sin duda, con mayores elementos de juicio de lo que ha sido el TLCAN.

La negociación regional de libre comercio de América del Norte se convirtió en el primer tratado comercial en el mundo que incluía la regulación sobre propiedad intelectual (capítulo 17), que además superaba a los Acuerdos de Propiedad Intelectual relativos al Comercio -ADPIC, TRIPS, por sus siglas en inglés- en el marco de la Organización Mundial del Comercio (OMC). El TLCAN se convertía en el modelo a seguir por la omc.

Aunque Estados Unidos mantenía desde tiempo atrás fuertes vínculos comerciales, comprendidas las transacciones bilaterales de tecnología con Canadá y México, en este acuerdo regional se advertía la decisiva influencia de las firmas americanas para proteger con particular meticulosidad sus innovaciones tecnológicas, como no lo habían hecho en el pasado con Japón y los países del Sudeste asiático, actualmente importantes competidores tecnológicos internacionales.

Este hecho implicaba enormes desafíos para México por el sustantivo rezago económico y tecnológico frente a sus dos países vecinos del norte. Por un lado, se abrían enormes oportunidades para México con los importantes flujos de conocimiento tecnológico que circularían de manera preferencial. Pero, por el otro, las obligaciones en materia de propiedad intelectual se erigían como considerables obstáculos para desarrollar la tecnología localmente. Especialmente si México no invertía en ciencia y tecnología y en investigación y desa- 
rrollo (ID) a una tasa superior que sus socios comerciales para disminuir las brechas tecnológicas y de desarrollo que los separaban. Así, en el capítulo 17 del TLCAN se convinieron los acuerdos en materia de propiedad intelectual como un gran muro al nuevo conocimiento tecnológico, que se extenderían a diversos campos como el de las tecnologías de la información y la comunicación (TICS), el sector bio-farmacéutico y otros más, para la nación de menor desarrollo, la que no poseía aún las necesarias capacidades de absorción tecnológica y de innovación.

A más de 20 años de la adopción de los ADPIC y la firma del TLCAN, las exportaciones manufactureras mexicanas de mediana e intensiva tecnologías han registrado un importante crecimiento. Sin embargo, ni la actividad inventiva ni el crecimiento económico de México parecen haber aumentado como se esperaba. En tal contexto, nos interesa analizar si las reformas a los derechos de propiedad intelectual han incentivado la innovación endógena o, si por el contrario, se ha reforzado la dependencia tecnológica extranjera de México. Asimismo, estimar el efecto del número de patentes concedidas a titulares residentes en la tasa de crecimiento económico y de éste en el número de novedades patentadas. En tal sentido, las preguntas centrales que constituyen el eje de esta investigación son: ¿Quién ha sido el beneficiario de la reforma de patentes puesta en marcha en 1991 ? ¿Las firmas locales han sido capaces de beneficiarse de las derramas de conocimiento y los incentivos del sistema de propiedad intelectual? ¿Cuál ha sido la relación recíproca entre la actividad inventiva endógena patentada y el crecimiento económico?

El objetivo de esta investigación es analizar empíricamente los efectos de la adopción de los ADPIC y la incorporación al TLCAN en la actividad inventiva endógena y la relación entre patentes y crecimiento económico y viceversa. En particular, primeramente se analiza cuál ha sido la evolución de las patentes de residentes en comparación a las de no residentes concedidas en el Instituto Mexicano de la Propiedad Intelectual de México durante el periodo de 1991 a 2015, identificando clases tecnológicas, tipo de titulares de los agentes con mayores patentes, con especial atención en las firmas extranjeras y nacionales con mayor patentamiento. Segundo, se propone un análisis econométrico para encontrar la relación cointegrante entre tales variables. Posteriormente, se desarrolla un modelo de vector de corrección de error donde se observa que la dinámica de las patentes y el PIB se ajusta en el equilibrio de largo plazo.

Sostenemos que las grandes beneficiarias del nuevo sistema de propiedad intelectual en México han sido las empresas transnacionales, especialmente las estadounidenses. La tecnología extranjera utilizada por las filiales extranjeras y las firmas nacionales, para producir en el país y después exportar, goza de una elevada 
protección mediante patentes ${ }^{1}$ con cuantiosas regalías y pagos. Las firmas extranjeras, que han realizado inversión extranjera directa o exportan tecnología a México, cuentan con el dominio de las patentes solicitadas y concedidas en el IMPI. En cambio, las empresas locales han sido marginales para patentar novedades endógenas, asociado al bajo esfuerzo destinado a la ID y la ausencia de políticas institucionales e industriales orientadas a incrementar las capacidades tecnológicas y de innovación. En consecuencia, se ha reforzado la dependencia tecnológica con el exterior, especialmente hacia los Estados Unidos.

Se espera que el creciente número de patentes de titulares mexicanos residentes pueda tener un impacto en el crecimiento económico, pero, contrariamente el incremento del PIB podría no afectar positivamente el aumento de patentes, debido a un gasto de ID/PIB aún bajo y una política industrial ausente.

Consideramos de especial relevancia identificar los efectos que se desprenden de la instauración de un sistema de propiedad intelectual totalmente vinculado al TLCAN en términos de difusión tecnológica y de innovación endógena.

El artículo se desarrolla en cuatro secciones. En la primera se resumen los principales antecedentes y los hallazgos teóricos y empíricos sobre la relación de la innovación y crecimiento económico. En la segunda se exponen brevemente los principales argumentos del debate de la adopción de los ADPIC, en particular, ponemos bajo la lupa la reforma de propiedad intelectual previa a la firma del TLCAN. En la tercera se caracteriza la evolución y la naturaleza de las novedades patentadas en México. En la cuarta se propone un modelo de cointegración para estimar los efectos de las patentes de residentes en el crecimiento económico de largo plazo y de éste en la creación de nuevas patentes. Finalmente, se presentan las principales conclusiones.

\section{ANTECEDENTES TEÓRICOS Y EMPÍRICOS DE LA INNOVACIÓN ASOCIADA A PATENTES Y CRECIMIENTO ECONÓMICO}

La preocupación por comprender el impacto del progreso tecnológico en el desarrollo y crecimiento económico se remonta a autores clásicos (Smith, Marx, entre otros). Pero corresponden a Schumpeter $(1911)^{2}$ dos contribuciones que han influenciado notablemente a diversos autores contemporáneos y enfoques teóricos (Aghion y Howith, 1998; Romer, 1990; Lucas, 1988; Barro, 1990; Grossman y Helpman, 1992, entre varios). La primera fue identificar todas las formas de inno-

${ }^{1}$ Además de marcas, licencias, diseños industriales.

${ }^{2}$ En 1911 se publicó la versión alemana de Teoría Económica del Desarrollo; la versión inglesa fue publicada en 1934. 
vación que se despliegan en la producción y su gestión y, su impacto en el desarrollo económico. La segunda, precisar que las innovaciones no ocurren de manera mágica sino como resultado de acciones arriesgadas, creativas, de empresarios (Scherer, 1999).

Aghion y Howitt (1998) se ubican más en el reconocimiento e interés de modelizar la teoría schumpeteriana. A su vez, los otros economistas, bajo la influencia inicial de Solow (1957) y retomando ideas schumpeterianas, desarrollaron las denominadas nuevas teorías del crecimiento endógeno al identificar las fuentes del progreso tecnológico, caracterizando su naturaleza endógena y su impacto en el crecimiento económico: ID (Romer, 1990), capital humano (Lucas, 1988), inversión en infraestructura pública (Barro, 1990), comercio internacional (Grossman y Helpman, 1992). El enfoque evolucionista (Nelson y Winter, 1993; Malerba et al., 1999) aborda el análisis de la innovación teniendo como eje la evolución de rutinas de aprendizaje, la incorporación de una variedad de innovaciones con una consiguiente selección acumulativa de las firmas y del mercado, aunque se sugiere que este proceso ocurre de manera automática y aleatoria (Antonelli, 2017).

Una aportación que engrandece la contribución de Schumpeter (1947) en la comprensión del papel de la innovación en el crecimiento económico corresponde al reconocimiento de las externalidades del conocimiento tecnológico como una oportunidad para engendrar nuevo conocimiento. En el proceso de absorción se hace uso del conocimiento incorporado en innovaciones precedentes, más allá del conocimiento que es apropiado por parte de los inventores o las firmas que financian la ID y/o las patentes (Antonelli, 2017).

Con el antecedente de las externalidades de imitación por parte de las firmas de los distritos industriales en el marco de un proceso de competencia y de un intento de pasar de heterogeneidad a homogeneidad en búsqueda de equilibrio (Marshall, 1920), y de la limitada apropiabilidad y derramas de conocimiento (Arrow, 1962), Schumpeter (1947) desarrolla la idea de las externalidades de conocimiento. Su contribución sienta las bases de la economía del conocimiento y la comprensión de cómo tales derramas pueden generar una dinámica de espiral creciente de interacción entre absorción del conocimiento tecnológico, creatividad, productividad, crecimiento económico, creatividad. La destrucción creativa que tiene lugar en el largo plazo, estará asociada a cambios inesperados en el producto y los factores del mercado. Si bien es cierto, frente a las crisis, habrá firmas que optarán por respuestas adaptativas, otras reaccionarán de manera creativa (véase discusión más detallada en Antonelli, 2017).

La discusión sobre la naturaleza y la apropiabilidad o no del conocimiento tiene gran relevancia para abordar los temas sobre propiedad intelectual. En particular, las patentes constituyen una protección de las novedades generadas y la 
posibilidad de apropiarse de los retornos de la inversión en ID realizada por las empresas más las ganancias (Baumol, 1993). Las patentes se identifican como un buen indicador entre firmas asociadas a los gastos en ID entre sectores (Grilliches, 1990; Hall y Harhoff, 2012); o, en una interacción inversa, el conocimiento acumulado en patentes fomenta mayor esfuerzo en ID y, en consecuencia, mayor potencial de innovación. Así, algunos autores advierten que la actividad en ID sustantiva global ocurre más bien en países desarrollados o de alto ingreso (PAI) y que ésta se relaciona positivamente con patentes (Coe y Helpman, 1995).

Los nuevos productos resuelven necesidades y abren nuevos mercados y por tanto, abonan positivamente a la competitividad; a su vez, los nuevos procesos mejoran la productividad. Al acrecentarse la competitividad y la productividad, el valor agregado en los sectores industriales también se expande, especialmente en aquellos intensivos en patentes (Hu y Png, 2013; Atun, Harvey y Wild, 2007; Thompson y Rushing, 1999). El progreso de la actividad empresarial se traduce en acumulación de capital y productividad, lo cual impacta positivamente la tasa de crecimiento económico (Park y Ginarte, 1997; Gould y Gruben,1996; Thompson y Rushing, 1996; Maradana, et al., 2017).

Los derechos de propiedad intelectual (DPI) y en particular, los derechos de patentes (DP), adquieren una relevancia crucial para la decisión de invertir en innovación (Gould y Gruben, 1996; Atun, Harvey y Wild, 2007; Imam, 2005; Park y Ginarte, 1997; Thompson y Rushing, 1996).

Así, una de las discusiones teóricas y de política se ha centrado en el fortalecimiento de los DPI para incentivar la innovación, con especial atención en los sistemas de patentes (SP). Tal debate ha sido relevante en el contexto de crecimiento exponencial del comercio internacional desde la década de los ochenta y particularmente en los noventa, cuando los procesos de producción adquieren el carácter global y las firmas transnacionales se movilizan para proteger sus invenciones; especial importancia se ha atribuido a los bienes intensivos en conocimientos, o de altas tecnologías. ${ }^{3}$ El nuevo conocimiento tecnológico revela parte de su naturaleza, la apropiabilidad y la exclusión (Romer, 1990).

Antecedidos por las discusiones en la Ronda de Uruguay en el marco del GATT, los Acuerdos de Propiedad Intelectual Relativos al Comercio (ADPIC) fue la propuesta regulatoria de la OMC, orientada a armonizar el fortalecimiento de las patentes y demás derechos de propiedad intelectual (Fink y Braga, 2005; Constatinos, et al., 2016). Algunos especialistas los identifican como estándares mínimos (Braga,

3"The importance of IPRs for trade has gained more significance as the share of knowledgeintensive or high-technology products in total world trade has doubled between 1980 and 1994 from 12 percent to 24 percent", (Fink y Braga, 2005, p. 19). 
1996). A fin de valorar las diferencias del efecto sobre el nivel de ID doméstica y extranjera, se compara lo que ocurre en regímenes de protección uniforme (estandarizada) y en regímenes con protección discriminatoria (Aoki y Prusa, 1993); así también, asumiendo que todas las firmas son eficientes en ID, el valor de la patentes puede influir tanto si la protección discriminatoria incrementase la ID doméstica (Idem).

El grado del fortalecimiento de los DPI estará vinculado al nivel de apertura comercial. La evidencia apunta a que una escasa apertura comercial no incentiva DPI fuertes y por tanto, estímulos para innovar endógenamente; en consecuencia, menor impacto en el crecimiento económico (Gould y Gruben, 1996). No obstante la armonización, los efectos de los sistemas de patentes SP pueden ser diferenciados entre países, se señala en algunos estudios.

Se prevé que un mayor fortalecimiento del sistema de patentes tendrá un efecto positivo significativo en crecimiento económico para países desarrollados (PD) y países en desarrollo (PED), (Constatinos et al., 2016). Aunque la adopción de los ADPIC en los PED pueden ser una etapa inicial del SP, y sus posteriores reformas podrían ser terreno fértil para fomentar el crecimiento económico (Imam, 2005; Gana, 1996).

En relación con la inversión extranjera directa (IED), particularmente la que corresponde a los flujos entrantes, puede influir en estimular positivamente el efecto para todos los países, en especial para los desarrollados (Constatinos et al., 2016). En los PED, el fortalecimiento de los SP pueden favorecer la IED, incrementar ID, o incluso fomentar la formación de científicos nacionales con capacidades creativas (Imam, 2005).

En contraste, otros autores precisan que los estándares internacionales de patentes (ADPIC) al ser desarrollados por países líderes, puede ocasionar muchos problemas para los países en desarrollo o aún más a los países de bajo ingreso (PBI), (Correa y Musungu, 2002). Al respecto, existen numerosos artículos que analizan el impacto del fortalecimiento de las patentes del sector farmacéutico y el efecto en el acceso a medicamentos en países pobres (Shadlen et al., 2011).

¿Por que estos países no están en condiciones de aprovechar los DPI para estimular la innovación y, por ende, el crecimiento económico?

En el caso de países con bajos niveles de educación, no se vislumbran niveles altos de protección de patentes debido a que sus habilidades para la creatividad y para la capitalización de las compensaciones serán menores (Park y Ginarte, 1997). Un nivel educativo frágil afectará negativamente la absorción de las derramas tecnológicas que ocurren a través de canales distintos, como el licenciamiento de patentes y en general del flujo de conocimiento que ocurre con el comercio. 
Conforme con los hallazgos del estudio de Maradana et al., (2017), sobre los efectos entre innovación y crecimiento económico del PIB per cápita, considerando seis indicadores de innovación y utilizando modelos cointegración, todos los países tienen beneficios, pero su magnitud dependerá de los canales por donde ocurran tales derramas y, además, qué montos de inversión se destinen a ID. En el caso de patentes, los países de mediano ingreso (PMI) parecen tener mayores beneficios que los países de bajo ingreso y los de alto ingreso (PBI) y (PAI), respectivamente.

En relación con la tecnología extranjera importada incorporada en bienes de capital (BK) se advierten efectos significativos en productividad en PMI y PAI, pero no en PBI. Aunque todos países muestran que tienen un efecto de alcance en la tecnología (techCatch), asociado a absorción de la tecnología extranjera en su forma incorporada (Maradara et al., 2017). Un incremento en capital humano especializado tendrá resultados efectivos en la absorción del conocimiento tecnológico.

Otras evidencias de Maradana et al., (2017): i) la apertura comercial favorece en mayor medida las derramas de conocimiento tecnológico cuando se atraen patentes extranjeras, que importan bienes de capital en países de mediano ingreso y con mayor significancia en países de bajo ingreso; $i i)$ reestructurar los DPI puede influir en una productividad superior; en países de mediano ingreso la mejora es de 40 por ciento, la productividad total de los factores se incrementa 15 por ciento; en comercio internacional el incremento es de 13 por ciento. Efectos mayores en PBI entre 0.49 y 0.24 por ciento.

El reconocimiento de las diferencias en innovación y el producto per cápita es necesario para que los países puedan prever un desarrollo sostenido. En el caso de Corea del Sur, su creatividad desplegada en el uso del sistema de patentes para promover capacidades tecnológicas ha sido clave para el crecimiento económico del país. En especial, la incorporación de novedades relativas a la información, la asistencia, del sistema educativo, y el fortalecimiento institucional y administrativo, con efectos positivos para el desarrollo de la industria nacional, resulta una referencia para países emergentes (Erstling y Strom, 2010). Cuando los países tienen bajos niveles de estabilidad institucional, no se prevén condiciones para un nivel fuerte del sistema de patentes (Thompson y Rushing, 1996).

Park (2011) evalúa la amplitud de la tecnología e intenta medir la fortaleza del sistema de propiedad intelectual en el marco del NAFTA, utilizando los indicadores: documentos de patentes, exportaciones, IED y licenciamiento.

Los hallazgos de Park (2011) permiten validar la importancia del TLCAN en la estimulación del comercio tecnológico entre los países miembros y con el resto del mundo. En relación con México se reconoce que es un gran depositario de flujos entrantes de tecnología, pero que no son originarios de éste. En contraste, los flujos tecnológicos entrantes y salientes de Canadá están asociados de manera significa- 
tiva al TLCAN. Finalmente, con respecto a Estados Unidos el comercio tecnológico con los miembros del TLCAN no es significativamente diferente al que tienen con los miembros no socios.

No obstante que la evidencia relativa a los beneficios o costos de la reforma de PI aún es limitada, Park (2011) considera que México aporta lecciones para otros mercados emergentes. En el largo plazo puede ser una fuente importante de crecimiento económico y un patrón determinante del comercio en conjunto y evolución de una ventaja comparativa. Sin embargo, esto depende del peso de los costos y beneficios.

Cuadro 1. Revisión de la literatura sobre innovación, patentes y crecimiento económico

\begin{tabular}{|c|c|c|}
\hline Autores & Problema investigación & Hallazgos \\
\hline $\begin{array}{l}\text { Atun, Harvey y Wild } \\
\text { (2007) }\end{array}$ & $\begin{array}{l}\text { Vínculos de innovación, PI, competitividad y } \\
\text { crecimiento económico y propuesta de polí- } \\
\text { ticas. Caso: E. U., Japón, China y UE. }\end{array}$ & $\begin{array}{l}\text { DPI clave en decisión de inversión en innovación para generar } \\
\text { crecimiento económico en economías basadas en el conoci- } \\
\text { miento. En especial, I+D en sectores intensivos tales como in- } \\
\text { dustrias de ciencias de la vida. Gobiernos: fortalecimiento DPI } \\
\text { en ambiente adecuado para comercializar innovación protegi- } \\
\text { da, asegurando retornos. }\end{array}$ \\
\hline Baumol (1993) & $\begin{array}{l}\text { Papel empresarios en invención, asociado a } \\
\text { las regalías. }\end{array}$ & $\begin{array}{l}\text { Innovación impactada por empresariado productivo y, su gra- } \\
\text { do de esfuerzo influenciado por correspondiente tamaño rela- } \\
\text { tivo de regalías. }\end{array}$ \\
\hline Braga (1996) & $\begin{array}{l}\text { Los ADPIC sientan los estándares mínimos } \\
\text { de los DPI. }\end{array}$ & \\
\hline Imam (2005) & $\begin{array}{l}\text { Extensión de beneficios mediante fortaleci- } \\
\text { miento de SP para economías en desarrollo. } \\
\text { Caso PED cercanos a países desarrollados: } \\
\text { China, India y Brasil. }\end{array}$ & $\begin{array}{l}\text { Mediante fortalecimiento del SP IOS PED pueden atraer IED, } \\
\text { incrementar ID, fomentar científicos nacionales para inventar } \\
\text { en el país nuevos medicamentos y, mejorar calidad salud. In- } \\
\text { corporación ADPIC en PED etapa inicial hacia reforma SP, re- } \\
\text { estructuraciones posteriores para promover crecimiento eco- } \\
\text { nómico. SP herramienta para } \Delta \text { crecimiento económico. }\end{array}$ \\
\hline $\begin{array}{l}\text { Coe and Helpman } \\
\text { (1995) }\end{array}$ & $\begin{array}{l}\text { Mayor parte de I+D tiene lugar en países de } \\
\text { OCDE, en especial PAI. }\end{array}$ & PIB podrá relacionarse positivamente con patentes. \\
\hline $\begin{array}{l}\text { Constatinos, Nellis y } \\
\text { Papageorgiadis (2016) }\end{array}$ & $\begin{array}{l}\text { Efectos del fortalecimiento de patentes en } \\
\text { crecimiento económico bajo ADPIC y papel } \\
\text { flujos entrantes de IED para mejorar esta re- } \\
\text { lación. }\end{array}$ & $\begin{array}{l}\text { Mayor fortalecimiento del SP, efecto positivo significativo en } \\
\text { crecimiento económico para PD y PED. Flujos entrantes IED, } \\
\text { papel intermedio en estimular positivamente el efecto para to- } \\
\text { dos los países, en especial para los desarrollados. }\end{array}$ \\
\hline $\begin{array}{l}\text { Correa y Musungu } \\
\text { (2002) }\end{array}$ & $\begin{array}{l}\text { Países menos desarrollados no podrían be- } \\
\text { neficiarse de la protección de patentes, por- } \\
\text { que los costos de las reformas o del SP está } \\
\text { por encima de beneficios potenciales. }\end{array}$ & $\begin{array}{l}\text { Estándares internacionales de patentes (ADPIC) desarrollados } \\
\text { por países líderes, puede ocasionar muchos problemas para } \\
\text { PED o PBI. }\end{array}$ \\
\hline $\begin{array}{l}\text { Erstling y Strom } \\
(2010)\end{array}$ & $\begin{array}{l}\text { Análisis de política de patente, legislación y } \\
\text { desempeño de Korean Intellectual Property } \\
\text { Office (KIPO); papel de estímulo al creci- } \\
\text { miento económico. }\end{array}$ & $\begin{array}{l}\text { Uso creativo de SP para promover capacidades tecnológicas } \\
\text { ha sido factor significativo en crecimiento económico de Corea } \\
\text { del Sur. La experiencia del sistema de patentes coreano de } \\
\text { gran utilidad para el desarrollo de la industria nacional (infor- } \\
\text { mación, asistencia, iniciativa de educación e institucionalidad } \\
\text { en su administración) de gran utilidad para países emergentes. }\end{array}$ \\
\hline
\end{tabular}


186 ECONOMÍA TeOrÍA y PrÁCTICA • Nueva Época, Número especial, vol. 4, agosto 2018

\section{Cuadro 1. Continuación}

\begin{tabular}{|c|c|c|}
\hline Gana (1996) & $\begin{array}{l}\text { Sin implementar estructuras políticas, econó- } \\
\text { micas y legales asociadas con sistemas de li- } \\
\text { bre comercio, los PED pueden no recoger los } \\
\text { beneficios de la protección de patentes. }\end{array}$ & $\begin{array}{l}\text { Reforma del SP de países en desarrollo es primera etapa hacia } \\
\text { un crecimiento económico significativo. }\end{array}$ \\
\hline $\begin{array}{l}\text { Gould y Gruben } \\
\text { (1996) }\end{array}$ & $\begin{array}{l}\text { Conexión entre fortalecimiento de DPI, (crean- } \\
\text { do incentivos dirigidos a búsqueda empresa- } \\
\text { rial -ID, inversión, innovaciones-) y crecimiento } \\
\text { económico. Ausencia estímulos a innovación } \\
\text { en régimen cerrado debido a ausencia compe- } \\
\text { tencia. Regímenes abiertos, potencial de em- } \\
\text { presas domésticas frente a extranjeras que } \\
\text { utilizan las más modernas tecnologías. }\end{array}$ & $\begin{array}{l}\text { DPI determinan significativamente el crecimiento económico. } \\
\text { Mejora de actividad empresarial, resulta en acumulación de } \\
\text { capital y productividad con impacto positivo en la tasa de cre- } \\
\text { cimiento económico. Mayor grado apertura comercial un ma- } \\
\text { yor nivel de protección de patente. Evidencia sugiere que DPI } \\
\text { fuertes no serían un estímulo a la innovación en países con } \\
\text { poca apertura. Los DPI tienen efecto en crecimiento económi- } \\
\text { co en economías relativamente abiertas. }\end{array}$ \\
\hline Hu y Png (2013) & $\begin{array}{l}\text { Impacto de cambio en DP efectivos en un } \\
\text { panel de } 54 \text { industrias manufactureras de } \\
72 \text { paises, 1981-2000. }\end{array}$ & $\begin{array}{l}\text { Mayores DP asociados al crecimiento de industrias más inten- } \\
\text { sivas en patentes; efecto mayor en países de mayor ingreso. } \\
\text { Entre1991-1995, el incremento DPE de Turquía y Singapur } \\
\text { asociado con crecimiento promedio mas elevado de otras in- } \\
\text { dustrias químicas y piel. Los DP asociados con rápido creci- } \\
\text { miento mediante factor de acumulación y elevamiento de pro- } \\
\text { ductividad. Hallazgos robustos que valida medición de } \\
\text { derechos de patentes e intensidad de patentes. }\end{array}$ \\
\hline Imam (2005) & $\begin{array}{l}\text { Extensión de beneficios mediante fortaleci- } \\
\text { miento de SP para economías en desarrollo. } \\
\text { Caso PED cercanos a países desarrollados: } \\
\text { China, India y Brasil. }\end{array}$ & $\begin{array}{l}\text { Mediante fortalecimiento del SP los PED pueden atraer IED, } \\
\text { incrementar ID, fomentar científicos nacionales para inventar } \\
\text { en el país nuevos medicamentos y, mejorar la calidad de la sa- } \\
\text { lud. Incorporación de ADPIC en PED etapa inicial hacia refor- } \\
\text { ma SP, reestructuraciones posteriores para promover desarro- } \\
\text { llo del crecimiento económico. SPP herramienta para } \\
\text { crecimiento económico. }\end{array}$ \\
\hline $\begin{array}{l}\text { Maradana, Pradhan, } \\
\text { Dash, Gaurav, Jayaku- } \\
\text { mar y Chatterjee } \\
\text { (2017) }\end{array}$ & $\begin{array}{l}\text { Relación entre innovación y crecimiento eco- } \\
\text { nómico del PIB per cápita utilizando mode- } \\
\text { los cointegración. Se prueba causalidad } \\
\text { Granger con seis indicadores de innovación: } \\
\text { patentes de residentes, patentes no residen- } \\
\text { tes, I+D, investigadores en I+D, exportacio- } \\
\text { nes de alta tecnología, artículos científicos y } \\
\text { tecnológicos de } 19 \text { países europeos, 1989- } \\
2014 \text {. }\end{array}$ & $\begin{array}{l}\text { Causalidad unidireccional y bidireccional entre innovación y } \\
\text { crecimiento económico. Variación entre países, dependiendo } \\
\text { de indicadores de innovación utilizados. Todos estrechamente } \\
\text { asociados al crecimiento económico; interacción en dos direc- } \\
\text { ciones ocurre sólo en algunos casos. Tecnología doméstica } \\
\text { fuente significativa del } \Delta \pi \text { en PAI, pero no en PMI y PBI. To- } \\
\text { dos se benefician de TechSpill, pero diferencias en canales que } \\
\text { dependen. Patentes generan techSpill en PMI, pero menos en } \\
\text { los PBI y PAI. Tecnología extranjera incorporada en BK impor- } \\
\text { tados tienen efectos significativos en productividad en PMI y } \\
\text { PAl, pero no en PBI. Todos países muestran efecto de tech- } \\
\text { Catch, asociado a absorción de la tecnología extranjera en su } \\
\text { forma incorporada. } \Delta \text { H efectos en } \Delta \text { techCatch. Mayor efecto } \\
\text { de apertura comercial en TechSpill al atraer patentes extranje- } \\
\text { ras que importar BK en PMI y PBI, más significativos en últi- } \\
\text { mos. Mejora DPI con efectos mayores en } \pi \text {. Mejora } 40 \text { por } \\
\text { ciento en DPI en PMI mejora } 15 \text { por ciento PTF; } 40 \text { por ciento } \\
\text { en comercio internacional } \Delta 13 \text { por ciento. Efectos mayores } \\
\text { en PBI entre } 0.49 \text { y } 0.24 \text { por ciento Propuesta de política: re- } \\
\text { conocer diferencias en innovación y PIB per cápita para man- } \\
\text { tener un desarrollo sostenido. }\end{array}$ \\
\hline Park y Ginarte (1997) & $\begin{array}{l}\text { Etapas intermedias en los vínculos entre DPI } \\
\text { y crecimiento económico. }\end{array}$ & $\begin{array}{l}\text { DPI estimulan factor de acumulación, a su vez determinante } \\
\text { de crecimiento económico. PBI, bajos niveles de educación sin } \\
\text { probabilidad de niveles altos, protección de patentes por la } \\
\text { habilidad para capitalizar compensaciones quedan fuera. }\end{array}$ \\
\hline
\end{tabular}




\begin{tabular}{|l|l|l|}
\hline $\begin{array}{l}\text { Park y Ginarte (1997); } \\
\text { Thompson y Rushing } \\
(1996)\end{array}$ & $\begin{array}{l}\text { Improbable que países sin sector activo en } \\
\text { ID innovación desarrolle una infraestructura } \\
\text { de DPI como una alta prioridad. }\end{array}$ & $\begin{array}{l}\text { Países con débil infraestructura ID (países de bajo ingreso) no } \\
\text { interesados en fortalecer sistema patentes y viceversa. }\end{array}$ \\
\hline $\begin{array}{l}\text { Thompson y Rushing } \\
(1996)\end{array}$ & $\begin{array}{l}\text { Relación entre protección de patentes y cre- } \\
\text { cimiento económico, 1970-1985. Mayores } \\
\text { niveles inestabilidad política no tendrán al- } \\
\text { tos niveles de protección de patentes. }\end{array}$ & $\begin{array}{l}\text { Fortalecimiento DPI no costoso incremento de poder monopó- } \\
\text { lico para PD a costa de PED. No es probable un elevado nivel } \\
\text { de patentes si un país tiene bajo niveles de estabilidad. }\end{array}$ \\
\hline $\begin{array}{l}\text { Thompson y Rushing } \\
\text { (1999) }\end{array}$ & $\begin{array}{l}\text { Vínculos entre impacto de protección de pa- } \\
\text { tentes en la PTF orientada al crecimiento } \\
\text { económico. Factores explicativos de dispari- } \\
\text { dades en niveles de protección en patentes. }\end{array}$ & $\begin{array}{l}\text { En PAl el impacto positivo de protección de patentes en cam- } \\
\text { bios de PTF y de ésta en crecimiento económico. }\end{array}$ \\
\hline
\end{tabular}

\section{El FORTALECIMIENTO DE LA PROPIEDAD INTELECTUAL EN MÉXICO}

La adopción de los Acuerdos de los Derechos de Propiedad Intelectual relativos al Comercio (ADPIC) en México en el año de 1991, en vísperas de la firma del Tratado de Libre Comercio de América del Norte (TLCAN), planteaba dos tipos de reflexiones. ${ }^{4}$ Por un lado, implicaba concluir con un sistema laxo de propiedad intelectual que había predominado en el país durante décadas e iniciar un sistema fuerte que asegurara la protección de las novedades tecnológicas extranjeras que ingresaran al país en el marco de la apertura comercial, mediante patentes, marcas, diseños industriales, entre otros, así como incentivar la innovación endógena. ${ }^{5}$ Por el otro, se advertían las severas limitaciones que tendría este nuevo sistema de propiedad intelectual (SPI) en un modelo de industrialización orientado a las exportaciones, al ser el país tecnológicamente dependiente, basado en gran medida en la imitación y con limitadas capacidades de innovación. En su momento se justificó que la reforma al SPI favorecería el flujo de nuevos conocimientos tecnológicos (nuevos productos y nuevos procesos) que influirían a desarrollar capacidades tecnológicas endógenas en el país, impulsando la innovación y, en consecuencia, el crecimiento económico y el bienestar de la población.

Pese a que México se había caracterizado por un sistema de propiedad laxa, la reforma a los derechos de propiedad intelectual (DPI) ocurrió de manera apresurada, mucho antes que la omc iniciara su cruzada entre los países integrantes para armonizar los DPI (Guzmán y Zúñiga, 2004; Guzmán y Viniegra, 2005). México

${ }^{4}$ En 1991 se reformó la Ley de Propiedad Industrial en el marco de los ADPIC y en 1994 se reconocieron los РCT en 1994. Ambos como mecanismos para la apertura comercial en el marco de la firma del TLCAN.

${ }^{5}$ Los ADPIC se extenderían a todos los países de la OMC para homogeneizar los sistemas de propiedad intelectual. El inicio sería en 1995 y se reconocía un periodo de transición para algunos países considerados en vías de desarrollo, como India y China. 
no sólo no contó como India y China de un periodo de 10 años de transición para incorporar los ADPIC, sino que, además, incorporó entre los capítulos del TLCAN uno que aseguraba mayor protección para los líderes mundiales de las tecnologías. Se consideraba que México se convertiría en la nueva cara de los nuevos desarrollos (Hussain, et al., 2015). Sin embargo, ¿cómo se delinearía el nuevo del desarrollo en México?

En los años noventa tuvo lugar un debate entre los especialistas en los temas relativos a propiedad intelectual sobre las asimetrías tecnológicas y la armonización de los DPI, con especial atención a los países en desarrollo (ICTSD, 20096). Uno de los sectores en que se expresó con mayor nitidez la preocupación fue el relativo al sector farmacéutico (véase: Guzmán y Zúñiga, 2004).

Varios estudios han identificado los bajos niveles de innovación de México y poca evidencia de que los ADPIC tuvieran efectos favorables para incentivarla durante el periodo del TLCAN (Lederman y Maloney, 2003, citado en Pack, 2007).

El estudio empírico comparativo sobre los efectos de patentes en el crecimiento económico sería de gran utilidad para una mejor comprensión del significado en términos del mercado regional. Sin embargo, este estudio sólo se concentra en México, aunque retomando algunos datos comparativos.

\section{EVOLUCIÓN DE LAS PATENTES DE RESIDENTES Y NO RESIDENTES EN MÉXICO}

México no había sido un país destacado por su actividad innovadora en las décadas previas al TLCAN. Sin embargo contaba con algunas capacidades de innovación, que es posible constatar con las patentes solicitadas y concedidas en México y así también en otras oficinas de patentes como la USPTO.

Conforme con las bases de patentes del Instituto Mexicano de la Propiedad Intelectual (IMPI), los residentes contaban con más solicitudes de patentes en la década de los ochenta que en los noventa cuando entraron en vigor los ADPIC y el TLCAN. En efecto, los agentes residentes de México habían solicitado 704 patentes en 1980, pero en el año 2001 cuando se adoptaron los ADPIC éstas descendieron a 564; es decir, una caída de -2 por ciento promedio anual. En 1994, con el inicio del TLCAN, las solicitudes de patentes de residentes descendieron aún más (498); con

${ }^{6}$ En el documento The Global Debate on the Enforcement of Intellectual Property Rights and Developing Countries del Internacional Centre for Trade and Sustainable Development (ICTSD) hay dos posturas opuestas. Por un lado, Cartsen Fink con su ensayo titulado "Enforcing Intellectual Property Rights: an Economic Perspective" y del otro, Carlos M. Correa con "The Push for Stronger Enforcement Rules: Implications for Developing Countries". 
respecto a 1980 la tasa de decrecimiento anual fue de -3.10 por ciento. El estancamiento de la actividad innovadora nacional patentada prosiguió en los años noventa y la primera década del siglo XXI. La recuperación se asoma desde el año 2009 con 822 solicitudes hasta alcanzar 1,364 solicitudes en el año 2015. No obstante que las solicitudes de patentes de nacionales aumentaron más del doble de 1991 a 2015, la brecha con respecto a las de extranjeros creció sustancialmente.

En efecto, las solicitudes de patentes de los agentes no residentes sometidas al IMPI han sido notablemente superiores a las de residentes. Durante la década de los ochenta el número de solicitudes de agentes extranjeros fue elevada, pero se mantuvo estancada; de 4,768 solicitudes en el año 1980 disminuyeron a 4,400 en el año 1990. Pero, con la adopción de los ADPIC y la puesta en marcha del TLCAN en 1994 se registra un sustantivo incremento; en 2001 y 2007 las solicitudes de no residentes ascienden a 9,446. Probablemente, la crisis de 2009 influyó en el descenso durante dos años, hasta lograr una recuperación en 2015. En suma, el crecimiento de las solicitudes de patentes de extranjeros fue dinámico durante 1991-2015, 5.42 por ciento, promedio anual, y la tendencia se asemeja a la del total de solicitudes (5.27 por ciento de TCPA). En contraste, las solicitudes de residentes sólo alcanzaron una tasa de crecimiento de 3.75 por ciento en el mismo periodo (véase gráfica 1).

El dominio de las solicitudes de agentes extranjeros sobre las nacionales se confirma al estimar la relación de dependencia tecnológica. Del total de las solicitudes de patentes, recibidas por el IMPI en $1990(5,061), 13.06$ por ciento $(661$ patentes) correspondió a los nacionales y 86.94 por ciento $(4,400)$ a los extranjeros. Lo anterior, implica una relación de dependencia tecnológica de $6.72^{7}$. A lo largo del periodo en que se concentra nuestro estudio, los extranjeros superaron su porcentaje de participación en el total de las solicitudes y contribuyeron a que la relación de dependencia aun fuera mayor. Así en 2015, se registraron 1,364 solicitudes de residentes y 16,607 de no residentes, que representaron 7.55 y 92.45 por ciento respectivamente. La relación de dependencia se duplicó (12.25).

Durante 1980-1990, previo a la adopción de los ADPIC y TLCAN, las patentes concedidas a residentes representaron 7 por ciento (con 1,708 patentes acumuladas) y las patentes a no residentes 93 por ciento (con 22,375 patentes acumuladas). Posterior al fortalecimiento del sistema de patentes en México, la participación porcentual de los nacionales en las patentes concedidas durante 1991-2015 sólo fue de 3 por ciento (con 4,986 patentes acumuladas) y los extranjeros de 97 por ciento. (con 168,902 patentes acumuladas).

${ }^{7}$ La relación de dependencia es el número de patentes de no residentes (extranjeros) entre el número de patentes de residentes (nacionales). 
190 Economía TeORía y PRÁCtica • Nueva Época, Número especial, vol. 4, agosto 2018

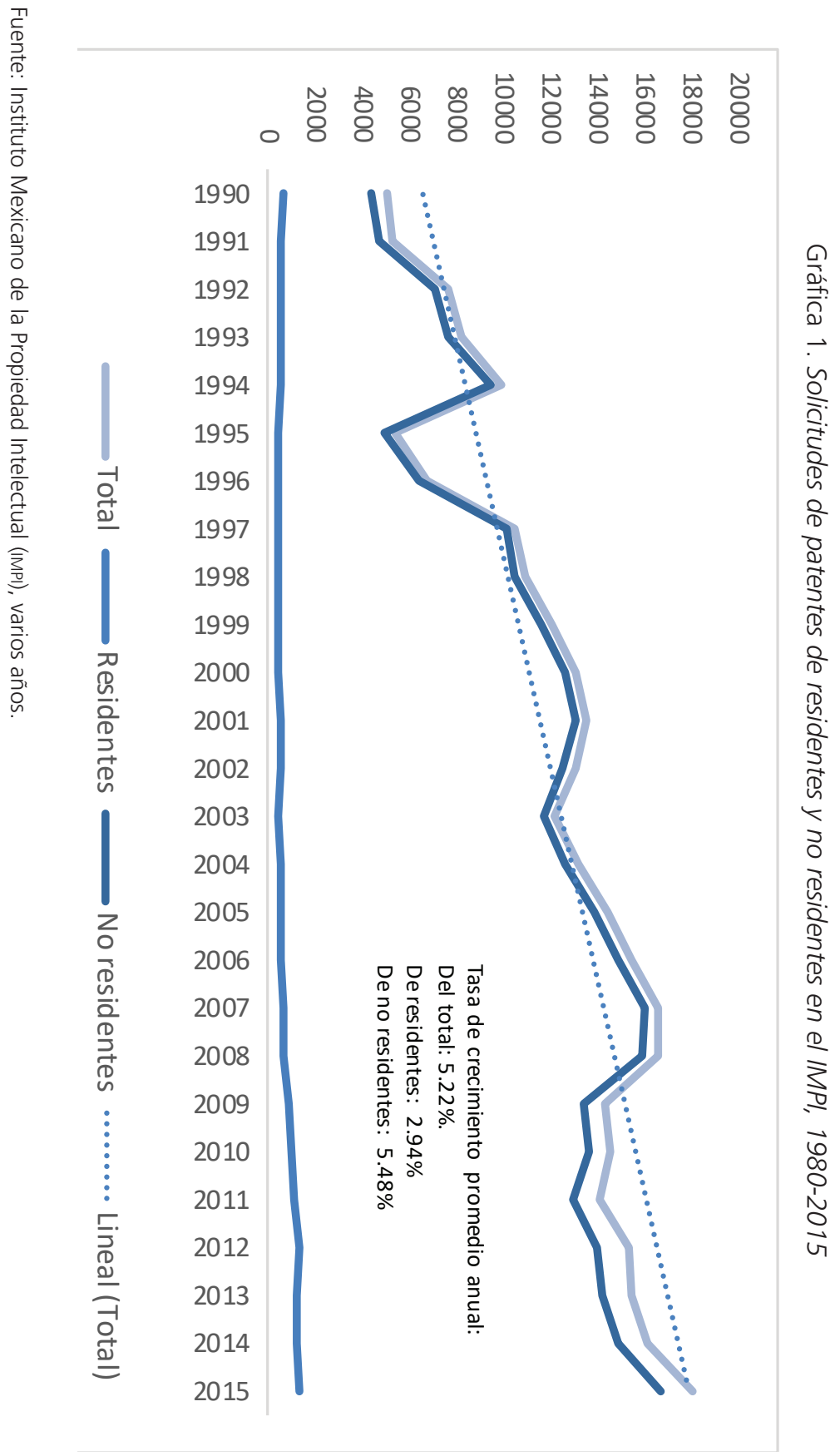




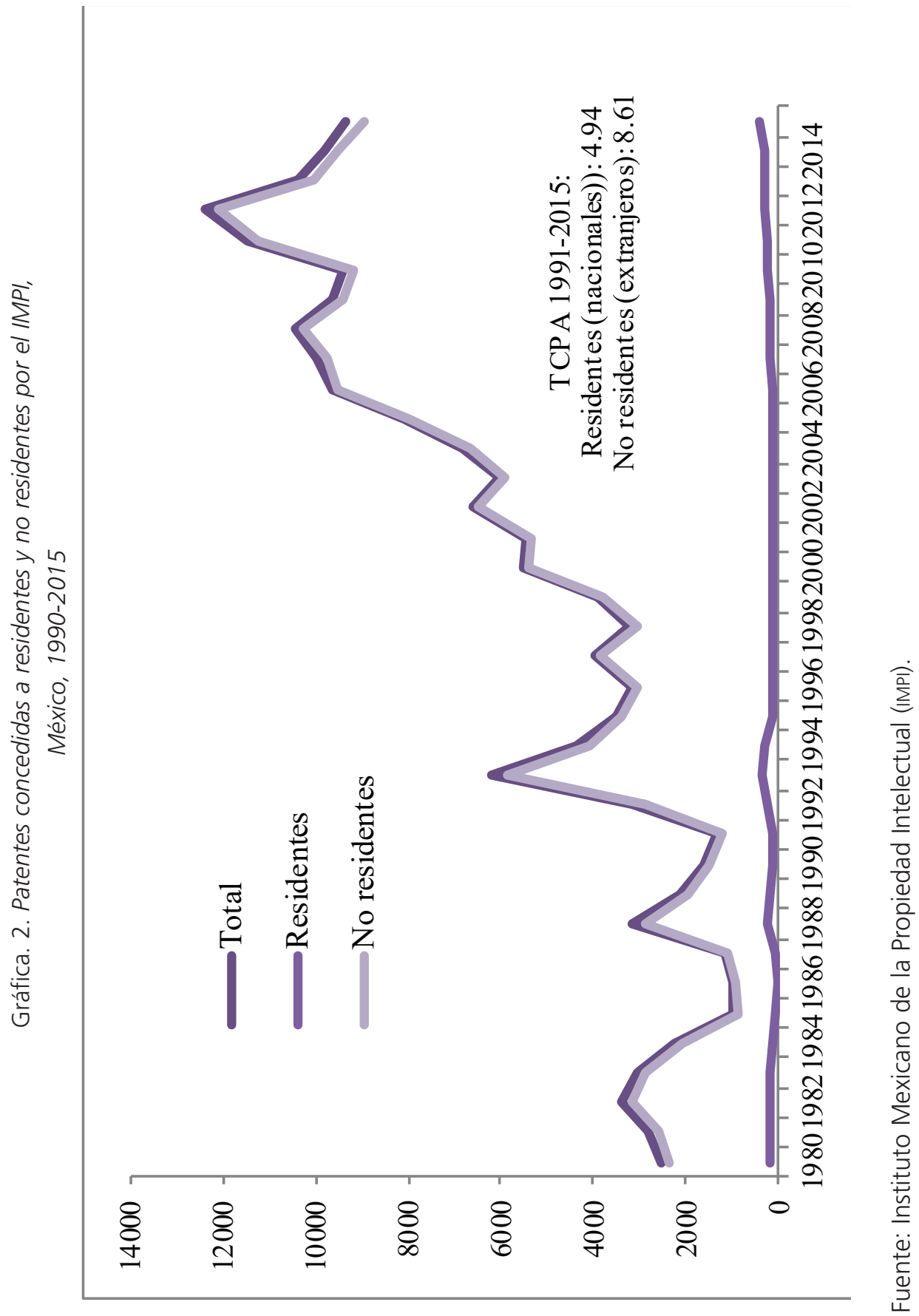


Mientras que en la década de los ochenta hay un decremento promedio anual para las patentes concedidas a residentes y no residentes $(-2.72$ por ciento y 4.59 por ciento, respectivamente), después de la reforma a los DPI se advierte un crecimiento sustantivo para los nacionales (4.94 por ciento promedio anual) y mayor para los extranjeros (8.61 por ciento) (véase gráfica 2$)$. La tendencia de crecimiento de patentes concedidas de no residentes es muy similar a la total.

\section{III.1 ¿De qué países son los titulares de las patentes de no residentes en el IMPI?}

La importancia de Estados Unidos como socio comercial para México, se advierte en la mayor participación en el número de patentes solicitadas y concedidas con respecto a otros países extranjeros que también destacan (Alemania, Francia, Japón, Reino Unido y Suiza). El vecino país de América del Norte obtuvo la concesión de 957 patentes en el IMPI en 1990. El sustantivo incremento de patentes concedidas ocurrió posterior a las reformas de los DPI; de 1990 a 2015 las patentes concedidas a titulares estadounidenses registraron una tasa de crecimiento de 6.16 por ciento. Aunque con un menor nivel, los demás países también observan un crecimiento dinámico en las patentes concedidas en el mismo periodo, especialmente Suiza (9.92 por ciento), Japón ( 8.86 por ciento) y Alemania ( 8.25 por ciento).

En el periodo de estudio 1990-2015, Estados Unidos supera la mitad de patentes concedidas ( 55 por ciento). Con una participación mucho muy inferior se sitúa Alemania (6 por ciento). Francia, Japón y Suiza tienen una participación similar. En otros se sitúan un conjunto de países, cuyas patentes concedidas alcanzan 18 por ciento del total.

\section{III.2 ¿En qué áreas tecnológicas los nacionales y los extranjeros patentan más?}

La clasificación de las patentes concedidas se realiza mediante las siguientes áreas tecnológicas: 1) Artículos de uso y consumo; 2) Técnicas industriales diversas; 3) Química y metalurgia; 4) Textil o papel; 5) Construcciones fijas; 6) Mecánica, iluminación calefacción, armamento y voladuras; 7) Física y, 8) Electricidad; en las primeras tres áreas se concentran más patentes concedidas a residentes concedidas durante el período 1990-2015, con 26, 20 y 21 por ciento del total, respectivamente. La tasa de crecimiento anual mayor en las patentes concedidas ocurrió en el área de física (10.54 por ciento), pese al aún bajo nivel de patentes. A su vez, otras 
Gráfica 3. Patentes concedidas a no residentes por el IMPI, por país, 1990-2015

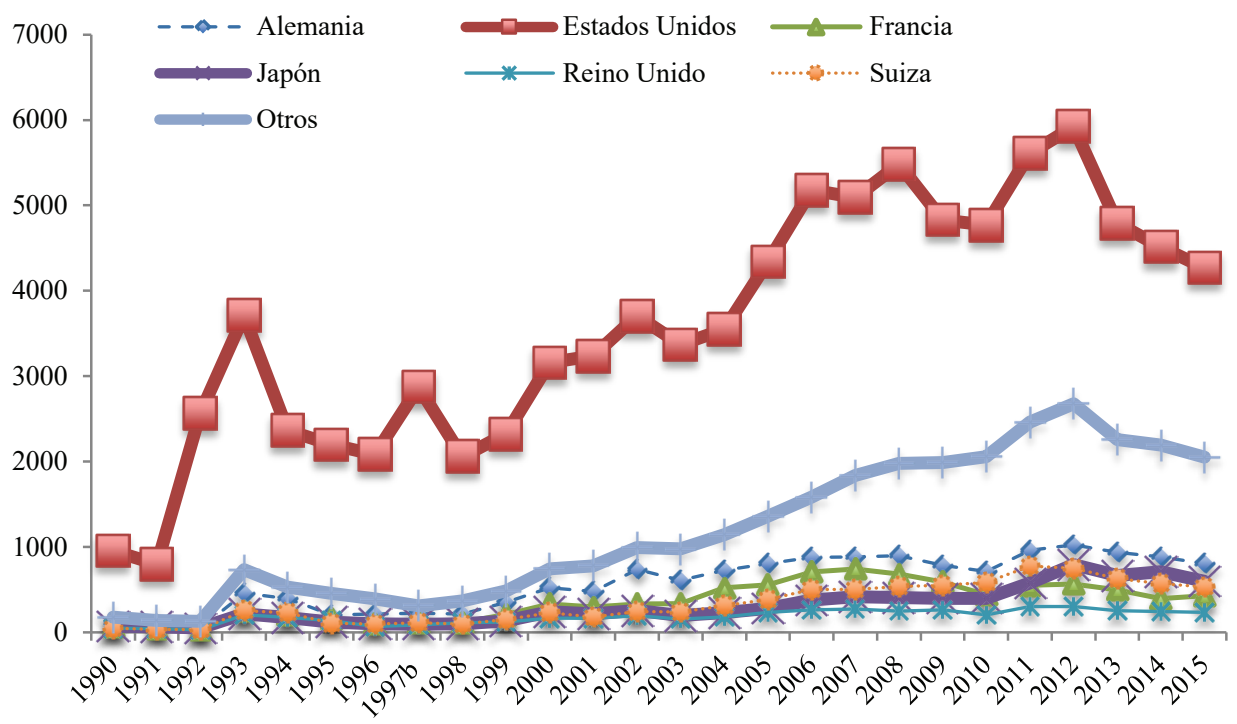

Fuente: IMPI en Cifras, varios años. De 1990 a 1992: SIGA-IMPI.

Gráfica 4. Distribución de las patentes concedidas a no residentes en el IMPI, 1990-2015

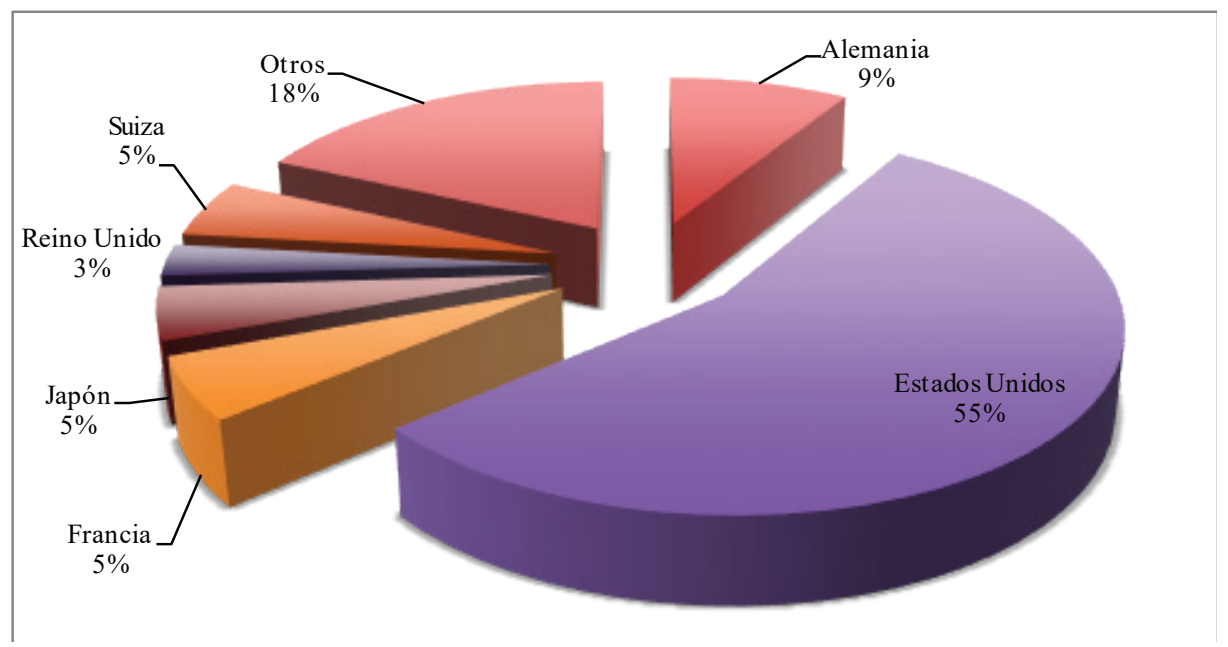

Fuente: IMPI en Cifras, varios años. De 1990 a 1992: SIGA-IMPI. 
Gráfica 5. Patentes concedidas a residentes por área tecnológica,

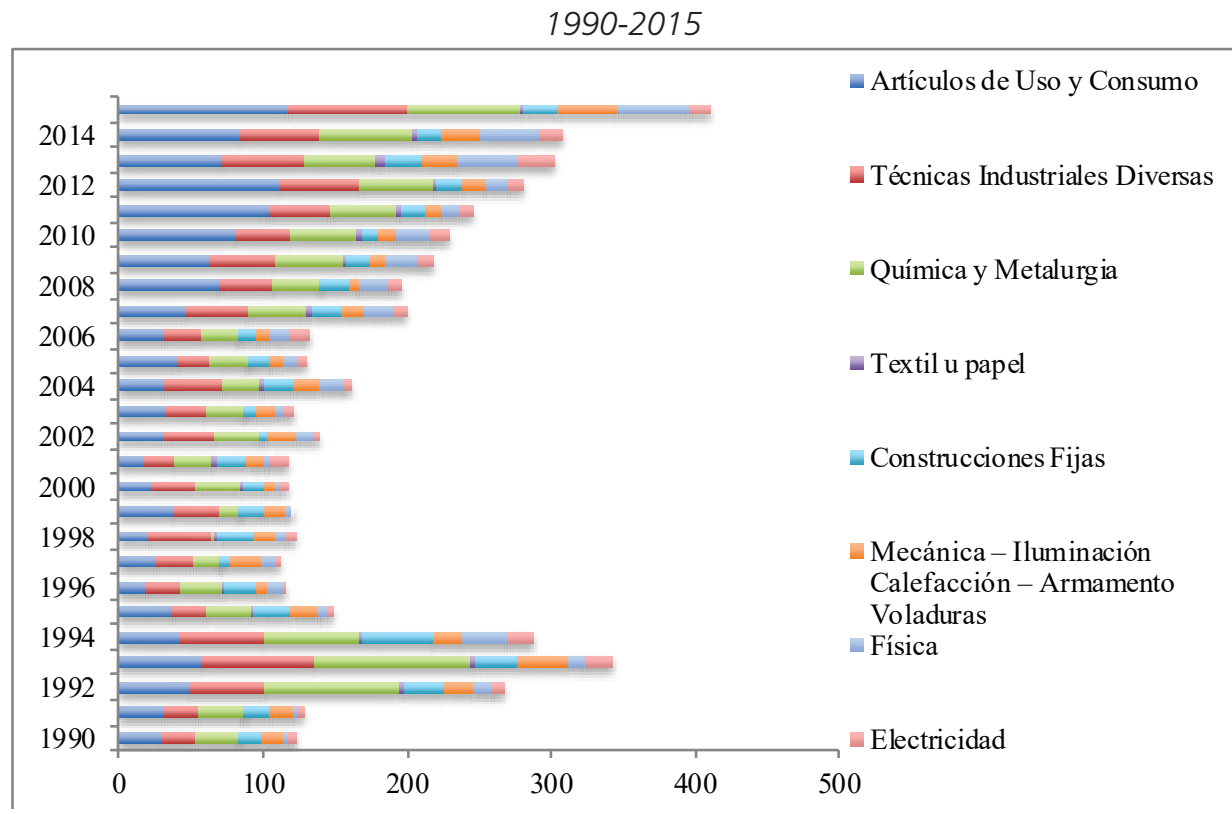

Fuente: IMPI en Cifras, varios años. De 1990 a 1992: sIGA-IMPI.

áreas que mostraron dinamismo en su crecimiento son: artículos de uso y consumo ( 5.63 por ciento promedio anual), técnicas industriales diversas (5.22 por ciento) un poco menor en química y metalurgia (4.09 por ciento).

En lo que concierne a las patentes concedidas a extranjeros, aquellas de Artículos de uso y consumo, Técnicas industriales diversas y Química y metalurgia acumularon más de 47 mil; 32 mil y cerca de 38 mil patentes respectivamente entre 1990 y 2015; en conjunto, éstas representan 59 por ciento del total. Destaca el año 2000 cuando las patentes concedidas en las dos primeras clases casi se duplicaron. Además de ser el número de patentes extranjeras sustantivamente superior al de nacionales, también la dinámica de crecimiento en todo el periodo estudiado (1990-2015) fue mayor, especialmente en artículos de uso y consumo (16.43 por ciento), incluyendo las áreas de física y electricidad (11.9 por ciento anual en cada una) y construcciones fijas (10.91 por ciento).

Comparando la participación porcentual del total de las patentes concedidas a residentes y no residentes en México por áreas tecnológicas, observamos que el predominio inicial de las segundas se refuerza en los últimos 15 años, acercándose al dominio completo. En consecuencia, la dependencia tecnológica (número de 
patentes de no residentes / número de patentes de residentes) de México se acrecentó, duplicándose en la mayoría de las áreas. Una área tecnológica que sobresale por su dependencia tecnológica es Electricidad, al pasar de una dependencia tecnológica de 45.2 en 1990-2000, a otra de 90.8 por ciento en 2001-2015. Este hecho, pone en evidencia la ausencia de política industrial asociada al magro esfuerzo en investigación y desarrollo; lejos de incentivar a las instituciones y empresas nacionales para innovar endógenamente en la generación de la energía eléctrica. Asimismo, para desarrollar otras fuentes energéticas ecológicas que abonaran a preservar el medio ambiente y al bienestar de la sociedad.

La sustantiva dependencia tecnológica no sólo se expresa en áreas vinculadas a los nuevos paradigmas tecnológicos, sino también en áreas de menor intensidad tecnología como la industria textil o del papel, donde la tasa de dependencia tecnológica pasó de 54.1 en 1990-2000 a 67.6 por ciento en 2001-2015 (véase cuadro 2). En artículos de consumo se pasó de 16.36 a 44.09 por ciento, lo cual constata la creciente dependencia en bienes que forman parte de la canasta de consumo de los habitantes de México, donde predominan marcas de empresas transnacionales.

Gráfica 6. Patentes concedidas a no residentes por área tecnológica, 1990-2015

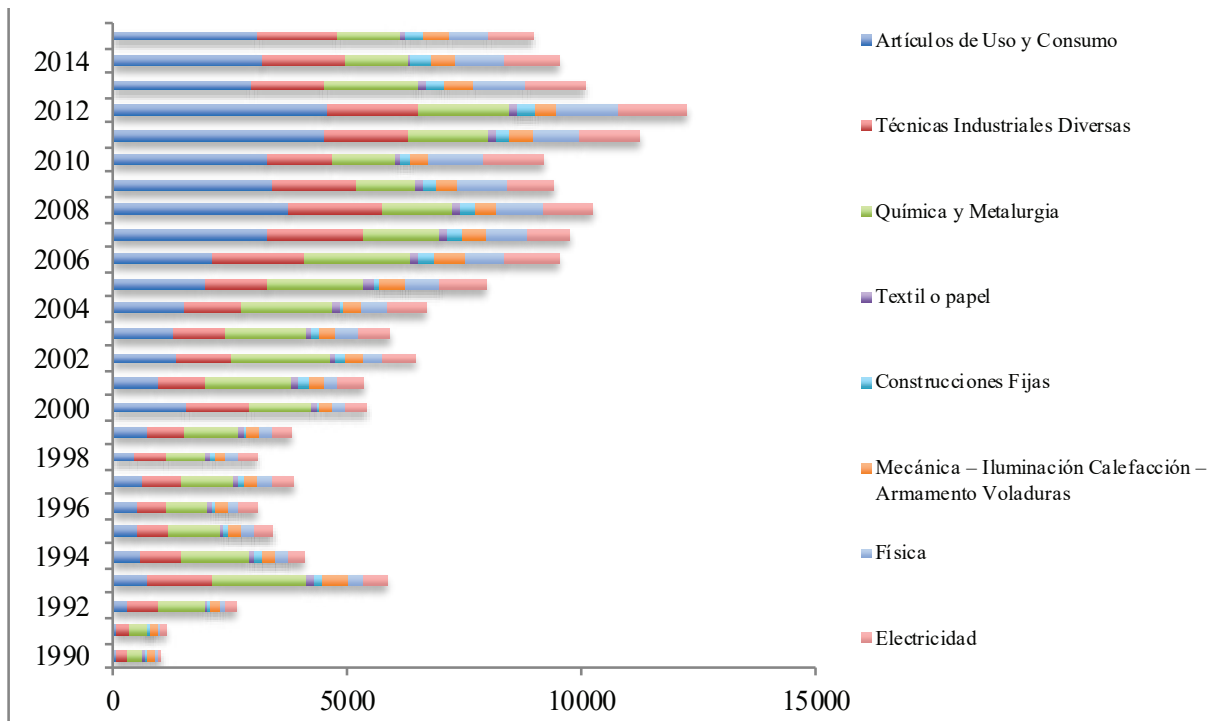

Fuente: IMPI en Cifras, varios años. De 1990 a 1992: SIGA-IMPI. 
196 ECONOMÍA TeORÍA y PRÁCTICA • Nueva Época, Número especial, vol. 4, agosto 2018

Cuadro 2. Distribución porcentual de patentes concedidas en el IMPI a residentes y no residentes por área tecnológica (\%)

\begin{tabular}{|c|c|c|}
\hline & $1990-2000(\%)$ & $2001-2015(\%)$ \\
\hline 1. Artículos de Uso y Consumo/ Residentes & 5.76 & 2.22 \\
\hline 1. Artículos de Uso y Consumo/ No residentes & 94.24 & 97.78 \\
\hline 1. Artículos de Uso y Consumo/ Total & 100 & 100 \\
\hline 1. Dependencia tecnológica & 16.36 & 44.09 \\
\hline 2. Técnicas Industriales Diversas/ Residentes & 5.98 & 2.58 \\
\hline 2. Técnicas Industriales Diversas/ No residentes & 95.25 & 97.42 \\
\hline 2. Técnicas Industriales Diversas/ Total & 100 & 100 \\
\hline 2. Dependencia tecnológica & 20.03 & 37.77 \\
\hline 3. Química y Metalurgia/ Residentes & 3.70 & 2.31 \\
\hline 3. Química y Metalurgia/ No residentes & 96.30 & 97.69 \\
\hline 3. Química y Metalurgia/ Total & 100 & 100 \\
\hline 3. Dependencia tecnológica & 26.01 & 42.31 \\
\hline 4. Textil o papel/ Residentes & 1.81 & 1.46 \\
\hline 4. Textil o papel/ No residentes & 98.19 & 98.54 \\
\hline 4. Textil o papel/ Total & 100 & 100 \\
\hline 4. Dependencia tecnológica & 54.12 & 67.55 \\
\hline 5. Construcciones Fijas/ Residentes & 20.99 & 5.88 \\
\hline 5. Construcciones Fijas/ No residentes & 79.01 & 94.12 \\
\hline 5. Construcciones Fijas/ Total & 100 & 100 \\
\hline 5. Dependencia tecnológica & 3.76 & 16.02 \\
\hline 6. Mecánica - Iluminación Calefacción - Armamento Voladuras/ Residentes & 5.88 & 3.40 \\
\hline 6. Mecánica - Iluminación Calefacción - Armamento Voladuras/ No residentes & 94.12 & 96.60 \\
\hline 6. Mecánica - Iluminación Calefacción - Armamento Voladuras/ Total & 100 & 100 \\
\hline 6. Dependencia tecnológica & 16 & 28.45 \\
\hline 7. Física/ Residentes & 3.97 & 2.38 \\
\hline 7. Física/ No residentes & 96.03 & 97.62 \\
\hline 7. Física/ Total & 100 & 100 \\
\hline 7. Dependencia tecnológica & 24.21 & 40.94 \\
\hline 8. Electricidad/ Residentes & 2.16 & 1.09 \\
\hline 8. Electricidad/ No residentes & 97.84 & 98.91 \\
\hline 8. Electricidad/Total & 100 & 100 \\
\hline 8. Dependencia tecnológica & 45.19 & 90.77 \\
\hline
\end{tabular}

Fuente: estimación propia con base en IMPI.

El análisis de los efectos de la dependencia tecnológica puede abordarse desde diferentes aspectos. Uno de ellos es el relativo al enorme pago de regalías por el uso de patentes y marcas de estos bienes a los titulares extranjeros, el impacto en precios y acceso a los bienes, el ritmo de desarrollo económico y el acceso al bienestar social. 
Un caso especial corresponde a los medicamentos patentados, propiedad esencialmente de empresas farmacéuticas transnacionales. En ocasiones los tratamientos terapéuticos de frontera son de difícil acceso para la población enferma por sus elevados precios. El abastecimiento de medicamentos en tiempo y forma por parte de las firmas farmacéuticas se enfrenta a numerosos problemas, lo cual puede tener graves consecuencias para enfermos cuyos tratamientos deben ser continuos, sin interrupciones.

Las crisis sanitarias, como la ocurrida con la influenza AH1N1 en México en abril de 2009, tuvo efectos funestos para la salud de la población. También, se generó una enorme factura a pagar por moléculas antivirales (oseltamivir -Tamiflu de Roche), zanamavir (Relenza de Glaxosmithkline), amantdatina (Antifludes, Flustamin y Fluviatal). Lo anterior, no obstante los acuerdos de Doha que permiten a los gobiernos el uso de las flexibilidades en los ADPIC relativas a las licencias obligatorias considerando las emergencias nacionales de salud. Entre las consecuencias, el país perdió 1 por ciento en el PIB. Así, nos preguntamos ¿dónde quedaron las capacidades para producir vacunas y medicinas por parte de las instituciones públicas y la industria farmacéutica locales? Muy probablemente, la puesta en marcha de una política industrial y de innovación en la industria biofarmacéutica tendría efectos positivos para atender los problemas de salud, sin registrar elevados saldos deficitarios comerciales.

\section{Gráfica 7. Dependencia tecnológica de México por área tecnológica (patentes no residentes / patentes residentes)}

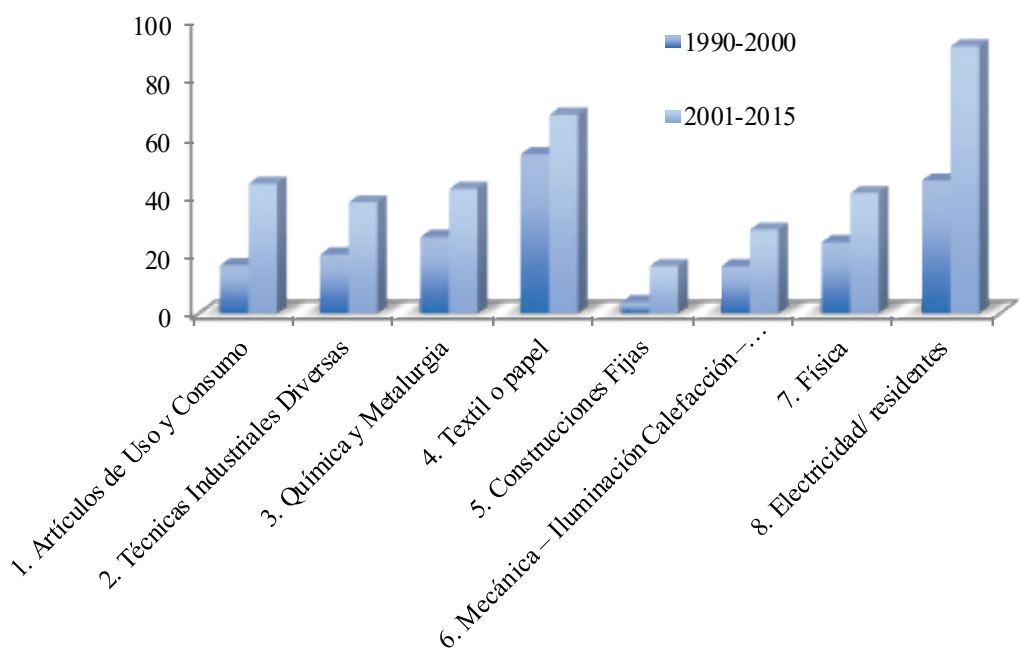

Fuente: estimación propia con base en IMPI. 
198 ECONOMÍA TeOrÍA y PrÁCTICA • Nueva Época, Número especial, vol. 4, agosto 2018

III.3 ¿Quiénes son los agentes y de qué áreas con mayor patentamiento?

Entre los principales agentes líderes en las patentes concedidas se encuentran las empresas extranjeras principalmente de los sectores bio-farmacéutico, TICs, automotriz. Las 30 empresas con más patentes concedidas en el año de 2012 obtuvieron 2,345 patentes, es decir, 19 por ciento del total de patentes concedidas por el IMPI (12,330). De éstas, 10 corresponden al sector bio-farmacéutico-químico: The Procter \& Gamble Company, F. Hoffman-La Roche AG, Novartis AG., Amgen Inc., Abbott Laboratories, Genentech, Inc, Colgate-Palmolive Company, Sanofi-Aventis, Astrazeneca AB y Janssen Pharmaceutica N.V. En conjunto estas acumularon 839 patentes concedidas y representan 36 por ciento del total en ese año.

Cuadro 3. Titulares con mayores patentes en 2012 y 2014

\begin{tabular}{|c|c|c|c|c|c|}
\hline \multicolumn{3}{|c|}{ Patentes otorgadas, 2012} & \multicolumn{3}{|c|}{ Patentes otorgadas, 2014} \\
\hline \multicolumn{2}{|l|}{ Titulares } & \multirow{2}{*}{\begin{tabular}{|c|c|} 
País \\
Estados Unidos
\end{tabular}} & \multicolumn{2}{|l|}{ Titulares } & \multirow{2}{*}{\begin{tabular}{|c} 
País \\
Corea de Sur
\end{tabular}} \\
\hline Quacomm Incorporated & 236 & & SAMSUNG Electronics Co. Ltd. & 166 & \\
\hline The Procter \& Gamble Company & 212 & Estados Unidos & The Procter \& Gamble Company & 135 & Estados Unidos \\
\hline F. Hoffman-La Roche AG & 134 & Suiza & BASF S. E. & 109 & Alemania \\
\hline Kimberly Clark & 126 & Estados Unidos & Schlumberger technology B.V. & 109 & Países Bajos \\
\hline Schlumberger Technology B.V. & 107 & Países Bajos & NISSAN Motor Co. Ltd. & 82 & Japón \\
\hline Novartis AG. & 103 & Suiza & NESTEC S. A. & 79 & Suiza \\
\hline Telefonaktiebolaget L.M. Ericsson (Publ) & 86 & Suecia & ZTE Corporation & 44 & China \\
\hline Nestec, S.A. & 79 & Suiza & $\begin{array}{l}\text { Telefonaktiebolaget L.M. Ericsson } \\
\text { (Publ) }\end{array}$ & 41 & Suecia \\
\hline Microsoft Corporation & 73 & Estados Unidos & Thomson Licensing & 23 & Francia \\
\hline Unilever N.V. & 72 & Países Bajos & $\begin{array}{l}\text { Universidad Nacional Autonóma } \\
\text { de México }\end{array}$ & 18 & México \\
\hline Panasonic Corporation & 70 & Japón & Janssen Pharmaceutica NV. & 17 & Bélgica \\
\hline Amgen Inc. & 69 & Estados Unidos & Haldor Topsøe A/S & 13 & Dinamarca \\
\hline Basf SE & 68 & Alemania & Nokia Siemens Networks OY & 13 & Finlandia \\
\hline Interdigital Technology Corporation & 68 & Estados Unidos & De La Rue International Limited & 9 & Reino Unido \\
\hline Ntt Docomo, Inc. & 67 & Japón & INDENA S.P.A. & 6 & Italia \\
\hline Abbott Laboratories & 67 & Estados Unidos & & & \\
\hline
\end{tabular}




\begin{tabular}{|c|c|c|}
\hline \multicolumn{3}{|c|}{ Patentes otorgadas, 2012} \\
\hline Titulares & & País \\
\hline E.I. du Pont de Nemours and Company & 65 & Estados Unidos \\
\hline Colgate-Palmolive Company & 62 & Estados Unidos \\
\hline Dow Global Technologies LLC. & 53 & Estados Unidos \\
\hline Genentech, Inc. & 51 & Estados Unidos \\
\hline Bayer Cropscience AG. & 50 & Alemania \\
\hline Thomson Licensing & 49 & Francia \\
\hline Sharp Kabushiki Kaisha & 49 & Japón \\
\hline Halliburton Energy Services, Inc. & 48 & Estados Unidos \\
\hline Motorola Mobility, Inc. & 48 & Estados Unidos \\
\hline $\begin{array}{l}\text { Fraunhofer-Gesellschaft zur Förderung der } \\
\text { Angewandten Forschung E.V. }\end{array}$ & 47 & Alemania \\
\hline Sanofi-Aventis & 47 & Francia \\
\hline Astrazeneca $A B$ & 47 & Suecia \\
\hline Janssen Pharmaceutica N.V. & 47 & Bélgica \\
\hline 3M Innovative Properties Company & 45 & Estados Unidos \\
\hline
\end{tabular}

Fuente: Instituto Mexicano de la Propiedad Intelectual.

Los titulares del sector de las Tics que destacan en 2012 con más patentes concedidas son las empresas de Suecia, Estados Unidos y Japón: Telefonaktiebolaget L.M. Ericsson (Publ), Microsoft Corporation Panasonic Corporation, Basf SE, Interdigital Technology Corporation, Thomson Licensing y Motorola Mobility, Inc.

El liderazgo de los principales 15 titulares en 2014 lo encabeza la empresa coreana Samsung; Procter \& Gamble Company, aunque no con el mismo nivel de patentes de 2012, mantiene una posición importante y se advierte la incursión de una empresa China, ZTE Corporation, con 44 patentes concedidas.

\section{III.4 ¿Beneficios o pérdidas de la propiedad intelectual} de México en el TLCAN?

La apropiabilidad del nuevo conocimiento tecnológico que se exporta e importa dentro la región de América del Norte ha sido uno de los aspectos centrales en el 
TLCAN. ${ }^{8}$ Especialmente, el país que detenta el liderazgo regional e internacional en materia de innovación en varias áreas tecnológicas, ha sido muy cauteloso protegiendo sus novedades mediante patentes y marcas en México. Tal como indicamos anteriormente, poco más de la mitad de las patentes de no residentes, corresponden al país vecino de la frontera norte.

La información estadística de pagos y recepción de regalías, licencias y otras compensaciones por concepto de patentes, marcas, diseños industriales u otras formas, son clave para dimensionar los beneficios o pérdidas de México en materia de propiedad intelectual fortalecida desde 1991 frente a los países socios en el TLCAN. En particular, nos permite identificar en cuanto los países son beneficiarios netos del sistema de propiedad intelectual.

Principalmente, las empresas estadounidenses reciben cuantiosas sumas de dólares por concepto de recepción de este tipo de ganancias y regalías del agregado por país (véase gráfica 8). Si bien es cierto que Estados Unidos es la nación que mayor pago efectúa por DPI, la recepción por regalías, licencias y otras compensaciones es tres veces mayor. Conviene señalar que los pagos por regalías los destina este país a otros industrializados, de los cuales obtiene tecnologías de frontera y no necesariamente a los países del TLCAN; eso se constata al observar los pagos relativos menores realizados por sus otros dos socios. En 1990, cuando ni México ni otros países de la OMC habían adoptado los ADPIC, Estados Unidos registró una recepción de 16.6 mil millones de dólares por regalías por DPI; sin embargo, en 1997 cuando México tenía cinco años de haber fortalecido su sPI y recién un año lo habían hecho otros países, el ingreso de Estados Unidos por tal concepto ascendió a 97 mil millones; es decir una tasa de crecimiento de 12.5 por ciento promedio anual. México registró una mayor tasa (14 por ciento), al pasar de 43 a 307 millones de dólares, pero con un vasto diferencial frente a Estados Unidos. A su vez, Canadá registró un incremento promedio anual de 3.9 por ciento en el mismo período.

Los diferenciales en el saldo de la recepción y pagos por DPI entre los países del TLCAN, se explican probablemente por las brechas tecnológicas y de innovación, que pueden apreciarse con indicadores que dan cuenta del esfuerzo que los países destinan a la economía del conocimiento: gasto en ID/PIB, al capital humano (investigadores por millón de habs.) y los productos que indican las capacidades tecnológicas de innovación alcanzadas: patentes solicitadas y concedidas (que además se transforma en un stock de conocimiento), marcas y exportaciones de alta tecnología. Estados Unidos supera a sus dos socios en todos estos indicadores, pero con mayor intensidad a México (véase cuadro 3).

${ }^{8}$ Como lo ha sido en otros tratados comerciales signados por México, incluso con mayor rigor y abarcando más áreas a proteger. 
Gráfica 8. Pagos y recepción de regalías por el uso de propiedad intelectual de los países del TLCAN, 2000- 2015

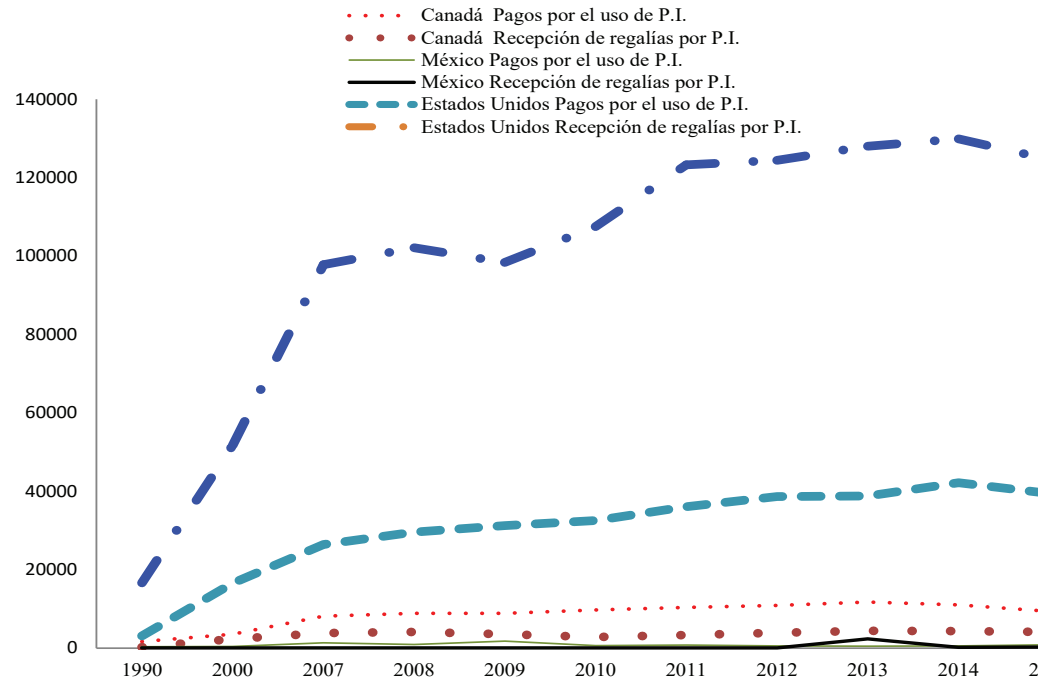

Fuente: Banco Mundial.

Cuadro 4. Indicadores de insumos y productos de la innovación tecnológica en los países del TLCAN, 2000- 2015

\begin{tabular}{|c|c|c|c|c|c|c|c|c|c|c|c|c|}
\hline \multicolumn{5}{|c|}{ Canadá } & \multicolumn{4}{|c|}{ México } & \multicolumn{4}{|c|}{ Estados Unidos } \\
\hline & 1990 & 2000 & 2010 & 2015 & 1990 & 2000 & 2010 & 2015 & 1990 & 2000 & 2010 & 2015 \\
\hline$I+D / P I B(\%)$ & .. & 1.9 & 1.8 & 1.6 & .. & 0.3 & 0.5 & 0.6 & .. & 2.6 & 2.7 & 2.8 \\
\hline $\begin{array}{c}\text { Investigadores/Mill } \\
\text { habts. }\end{array}$ & .. & $3,514.4$ & $4,649.2$ & .. & .. & 216.2 & 311.8 & .. & .. & $3,475.5$ & $3,867.0$ & .. \\
\hline $\begin{array}{c}\begin{array}{c}\text { Solic. Patente residentes } \\
\text { (número) }\end{array} \\
\end{array}$ & 2,549 & 4,187 & 4,550 & .. & 661 & 431 & 951 & .. & 90,643 & 164,795 & 241,977 & .. \\
\hline $\begin{array}{l}\text { Solic. Patentes no } \\
\text { residentes (número) }\end{array}$ & 24,375 & 35,435 & 30,899 & .. & 4,400 & 12,630 & 13,625 & .. & 80,520 & 131,100 & 248,249 & .. \\
\hline Marcas residentes & 13,948 & 22,080 & 20,449 & 21,348 & 15,863 & 36,698 & 68,928 & 81,100 & 106,693 & 251,220 & 236,826 & 283,230 \\
\hline Marcas no residente & 11,733 & 24,172 & 24,771 & .. & 9,579 & 23,023 & 25,529 & .. & 20,653 & 41,244 & 45,000 & .. \\
\hline $\begin{array}{c}\text { Pagos de regalías por uso } \\
\text { de P.I. (Mill dls.) }\end{array}$ & 1,664 & 3,564 & 9,731 & 9,384 & 380 & 406 & 658 & 872 & 3,140 & 16,607 & 32,551 & 39,495 \\
\hline $\begin{array}{c}\text { Recepción de regalías por } \\
\text { TT de P.I.(Mill. Dls.) }\end{array}$ & 235 & 2,324 & 2,814 & 4,126 & 73 & 43 & 88 & 307 & 16,640 & 51,807 & 107,522 & 124,665 \\
\hline $\begin{array}{c}\text { Saldo de la recepción y el } \\
\text { pago de las regalias }\end{array}$ & $-1,429$ & $-1,240$ & $-4,327$ & $-4,794$ & -307 & -363 & $-1,298$ & -832 & 13,500 & 35,200 & 71,323 & 72,503 \\
\hline $\begin{array}{c}\text { Exportaciones alta } \\
\text { tecnologia }(\%)\end{array}$ & 13.8 & 17.7 & 14.0 & 13.9 & 8.4 & 22.5 & 16.9 & 14.7 & 32.5 & 33.8 & 20.0 & 19.0 \\
\hline
\end{tabular}

Fuente: Banco Mundial. 


\section{PATENTES Y CRECiMiento ECONÓMICO: UN MODELO DE COINTEGRACIÓN}

En esta sección se examina la dinámica entre innovación y crecimiento económico de México durante el periodo 1991-2015 con base en un enfoque multivariado de causalidad tipo Granger para variables cointegradas. Particularmente, se desarrolla un modelo de cointegración para estimar los efectos de las patentes otorgadas por el Instituto Mexicano de Propiedad Industrial a residentes en el crecimiento económico de largo plazo; así también, cómo éste tiene un impacto en las actividades inventivas patentadas. Tal evaluación permitirá analizar la dinámica de innovación-crecimiento económico- innovación en el contexto de los ADPIC y el TLCAN. Primamente se especifican las fuentes de datos. Enseguida se especifica el modelo y finalmente se analizan los resultados.

\section{IV.1 Fuente de datos}

Las patentes concedidas a residentes por el Instituto Mexicano de la Propiedad Industrial (IMPI) es la variable proxy de innovación utilizada en esta investigación. Ésta nos da cuenta de la actividad inventiva endógena protegida mediante protección industrial. Cuando las patentes se escalan industrialmente y se difunden en los mercados adquiere el carácter de innovación, conforme con la literatura especializada (Grilliches, 1982). La base de datos de las patentes otorgadas a residentes se obtuvo del Sistema de Información de la Gaceta de la Propiedad Industrial del IMPI. Para efectos del modelo de cointegración se organizaron trimestralmente por la fecha de otorgamiento.

El producto interno bruto (PIB) trimestral de México del periodo 1990 a 2015, variable que nos permite estimar el crecimiento económico, se obtuvo de base de datos del INEGI estimado en pesos y se ajustó a precios constantes 2008.

\section{IV.2 Dinámica del crecimiento económico y de patentes durante 1990-2016}

La tendencia de crecimiento logarítmico del producto interno bruto y de las patentes concedidas del primer trimestre de 1990 al cuarto trimestre de 2016 se muestra en la gráfica 9. En el periodo de largo plazo considerado, se advierte una tendencia creciente del PIB real, que especialmente se aprecia posterior a la firma del TLCAN y con una caída durante la crisis económica de 2008-2009, que tuvo un impacto internacional y una posterior recuperación. 
En contraste, el crecimiento del número de patentes concedidas a residentes por trimestre durante el mismo periodo registra más bien una tendencia errática (véase gráfica 9).

No obstante, en las continuas variaciones durante todo el largo plazo es posible detectar diferentes ritmos de crecimiento; primeramente, tras haber sido fortalecido el sistema de propiedad intelectual con la adopción del ADPIC en 1991, que extendía la vigencia de las patentes a 20 años, se identifica un incremento sustantivo del primer trimestre de 1993 hasta el cuarto trimestre de 1994; posteriormente las patentes concedidas por trimestre registran seis trimestres de disminución y estancamiento. Hacia finales de 1996 se advierte una ligera recuperación, pero con muchas oscilaciones a la baja y a la alza que continúan al primer trimestre de 2013, incluso con ninguna patente en los trimestres: cuarto de 1991, segundo de 2004 y primero de 2013. Después de este último trimestre, la tendencia, aunque fluctuante, se advierte ascendente, llegando al valor de 125 patentes, superior al tercer trimestre de 1993, pero no con el nivel de los años previos.

Gráfica 9. Número de patentes y PIB en pesos constantes de 2008:

\section{Q1-2016Q4}

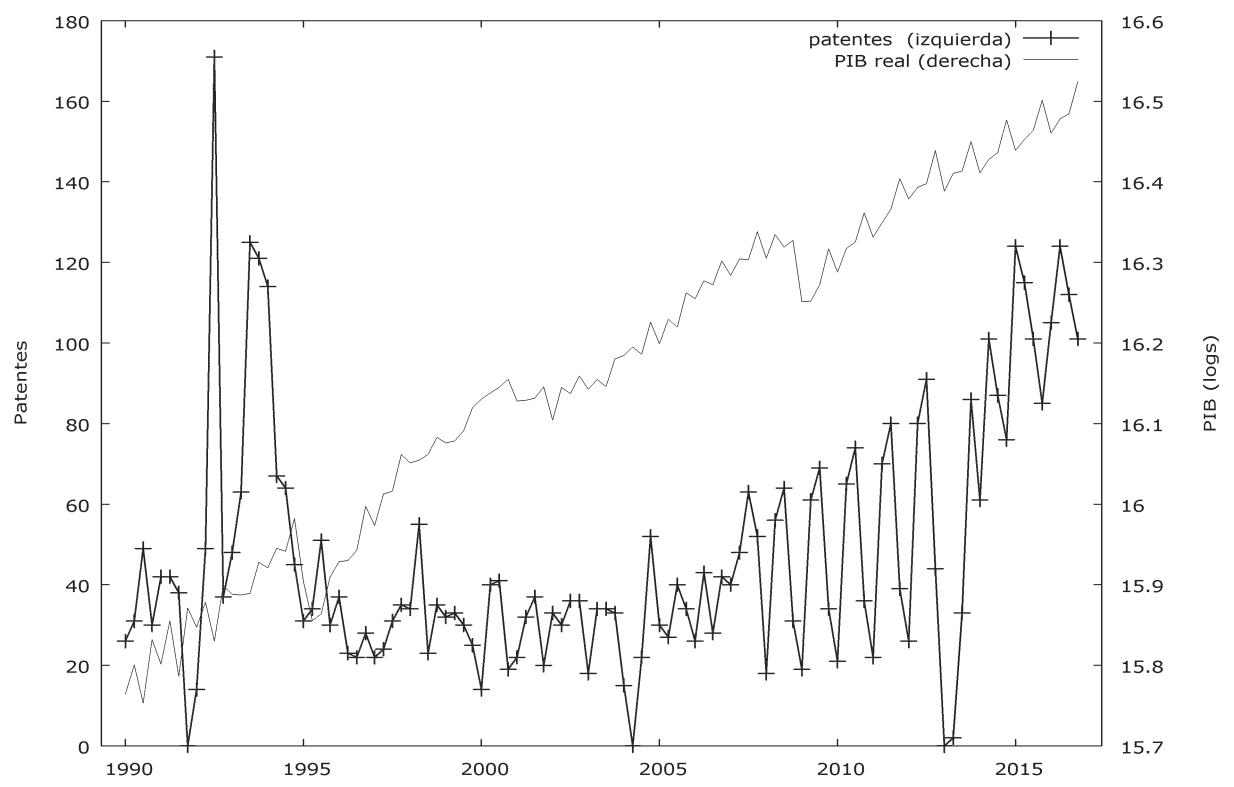




\section{IV.3 Análisis de las variables en el largo plazo}

Las pruebas de raíces unitarias de las series aplicadas tienen el propósito de determinar las condiciones de estacionariedad (orden de integración) de tales series analizadas (véase cuadro 3). De los resultados obtenidos en las pruebas de ADF y KPSS se infiere que las series del número de patentes y del PIB en logaritmos con base a precios constantes de 2008 pueden considerarse como no estacionarias en sus niveles y estacionarias en sus primeras diferencias. Por tanto, es conveniente realizar el análisis de las relaciones de largo plazo mediante las pruebas de cointegración de Johansen.

Conforme con la prueba de Johansen se supone la posibilidad de existencia de una relación cointegrante entre el PIB real y el número de patentes concedidas durante el periodo de análisis (cuadro 4). Con base en ese resultado, se procedió a estimar un modelo vectorial de corrreción del error (VECM) para analizar la dinámica que siguen ambas variables en torno a la relación de largo plazo sugerida por la prueba de Johansen.

Los resultados de la estimación del modelo vectorial de corrección del error muestran que en la ecuación del PIB existe una relación positiva entre los cambios en el número de patentes y la tasa de crecimiento del PIB real, con una elevada significancia para casi todos los rezagos considerados (véase cuadro 5). Lo anterior, sugiere que el incremento de invenciones patentadas, tras la inversión y el esfuerzo desplegado en investigación y desarrollo, puede tener un efecto positivo en la dinámica de la actividad económica. Así, es probable anticipar un mayor desempeño económico en la medida en que crece el número de patentes registradas. En consecuencia, la estimación del VECM permitiría confirmar la hipótesis de que la innovación impulsa el crecimiento económico, tal como otros autores lo han planteado.

Sin embargo, concerniente al efecto de la dinámica de crecimiento del PIB real en el cambio en el número de patentes concedidas, los resultados de la ecuación muestran que el impacto no es significativo (cuadro 5). Diferentes explicaciones pueden asociarse a este fenómeno. Una podría relacionarse con el bajo porcentaje del gasto destinado a la investigación y desarrollo con respecto al PIB en México durante todo el periodo analizado, erigiéndose como una importante limitante para extender la actividad inventiva patentada. Otra, probablemente se vincule a que el nivel de crecimiento económico no sea lo suficiente para incentivar mayores innovaciones, especialmente cuando el gasto destinado a la inversión y desarrollo es bastante inferior si se considera que México se encuentra en un mercado de comercio regional con países desarrollados. 
Cuadro 5. Pruebas de raíces unitarias y análisis de cointegración

\begin{tabular}{|c|c|c|c|c|c|c|}
\hline \multicolumn{7}{|c|}{ Prueba de raíz unitaria de Dickey y Fuller Aumentada (ADF) } \\
\hline Variable & & Rezagos & $t_{m}$ & Rezagos & $t_{b}$ & Rezagos \\
\hline Patentes & 0.0143108 & 3 & -1.43141 & 3 & -1.73181 & 3 \\
\hline PIB & 3.36756 & 9 & -0.818632 & 9 & -2.66218 & 9 \\
\hline Patentes & $-11.9977^{* * *}$ & 2 & $-11.9915^{* * *}$ & 2 & $-11.9931^{* * *}$ & 2 \\
\hline PIB & $-2.43208^{* *}$ & 8 & $-4.25125^{* * *}$ & 8 & $-4.26636^{* * *}$ & 8 \\
\hline \multicolumn{7}{|c|}{ Prueba de raíz unitaria de Kwiatkowski, Phillips, Schmidt y Shin (KPSS) } \\
\hline & \multicolumn{3}{|c|}{$\mathrm{KPSS}_{a}$} & \multicolumn{3}{|c|}{$\mathrm{KPSS}_{\mathrm{i}}$} \\
\hline Patentes & \multicolumn{3}{|c|}{$0.531624^{* *}$} & \multicolumn{3}{|c|}{$0.305326^{* * *}$} \\
\hline PIB & \multicolumn{3}{|c|}{$2.22739^{* * *}$} & \multicolumn{3}{|c|}{$0.214872^{* * *}$} \\
\hline Patentes & \multicolumn{3}{|c|}{0.0560665} & \multicolumn{3}{|c|}{0.0388105} \\
\hline PIB & \multicolumn{3}{|c|}{0.0413589} & \multicolumn{3}{|c|}{0.0292796} \\
\hline \multicolumn{7}{|c|}{ Pruebas de cointegración de Johansen (seis rezagos en el VAR) } \\
\hline Rango & \multicolumn{3}{|c|}{ Prueba de la traza } & \multicolumn{3}{|c|}{ Prueba de $\lambda_{\text {máx }}$} \\
\hline 0 & \multicolumn{3}{|c|}{$23.929^{*}$} & \multicolumn{3}{|c|}{$20.918^{* *}$} \\
\hline 1 & \multicolumn{3}{|c|}{3.0107} & \multicolumn{3}{|c|}{3.0107} \\
\hline
\end{tabular}

Así también, la enorme dependencia tecnológica de México asegura el acceso a nuevos productos importados al mercado nacional y nuevos insumos y procesos tecnológicos al parque industrial, pero la política industrial está ausente para fomentar el aprendizaje y la absorción de las derramas del conocimiento tecnológico en las firmas nacionales para internalizar la innovación endógena. La transferencia tecnológica (ТT) es indispensable para acercarse a la frontera tecnológica internacional, apoyadas por una adecuada gobernanza del conocimiento tecnológico y, desde luego, una participación creativa de empresarios (Antonelli, 2017). Es decir, la TT no será suficiente si hay carencia de empresarios con respuestas creativas frente a la competencia entre firmas, especialmente en presencia de mercados abiertos y las crisis económicas.

Conviene destacar que las pruebas de autocorrelación no sugieren presencia significativa de ese problema en los residuos del sistema, incluso hasta el rezago 24, sugiriendo la estabilidad del sistema estimado. Por tal razón se decidió proseguir con el análisis de las respuestas de las variables del sistema a impulsos en las mismas con el fin de considerar qué puede ocurrir en las variables ante presencias de choques que perturben la estabilidad del sistema (véase gráfica 10). 
206 ECONOMÍA TeORÍA y PrÁCTICA • Nueva Época, Número especial, vol. 4, agosto 2018

Cuadro 6. Sistema VECM estimado Variable dependiente: $P I B_{T}$

\begin{tabular}{|c|c|c|c|c|}
\hline \multicolumn{5}{|c|}{ VARIABLE DEPENDIENTE: $\Delta$ PIB $_{\mathrm{t}}$} \\
\hline & Coeficiente & Desv. TíPICA & ESTADISTICO T & VALOR P \\
\hline Constante & 4.6786 & 1.04494 & 4.477 & $2.26 \mathrm{E}-05^{* * *}$ \\
\hline РIBT-1 & -0.0916852 & 0.0963072 & -0.9520 & 0.3437 \\
\hline PIBT-2 & 0.0915298 & 0.0866119 & 1.057 & 0.2935 \\
\hline PIBT-3 & -0.179891 & 0.0776365 & -2.317 & $0.0228 * *$ \\
\hline PIBT-4 & 0.435967 & 0.0799939 & 5.45 & $4.54 \mathrm{E}-07$ *** \\
\hline РIBT-5 & 0.0318269 & 0.0917568 & 0.3469 & 0.7295 \\
\hline PATENTES T-1 & 0.00025169 & 7.99E-05 & 3.149 & $0.0022^{* * *}$ \\
\hline PATENTES T-2 & 0.00035678 & $8.45 \mathrm{E}-05$ & 4.221 & $5.91 \mathrm{E}-05^{* * *}$ \\
\hline PATENTES T-3 & 0.00016463 & $8.49 \mathrm{E}-05$ & 1.94 & $0.0556^{*}$ \\
\hline PATENTES T-4 & 0.00023375 & $8.36 \mathrm{E}-05$ & 2.797 & $0.0063^{* * *}$ \\
\hline PATENTES T-5 & 0.00023336 & $7.51 \mathrm{E}-05$ & 3.106 & $0.0026 * * *$ \\
\hline 1995Q2 & -0.0671826 & $0.0187731-3.579$ & $0.0006^{* * *}$ & \\
\hline $\mathrm{ECT}$ & -0.295085 & 0.0660368 & -4.468 & $2.33 \mathrm{E}-05^{* * *}$ \\
\hline
\end{tabular}

\begin{tabular}{|c|c|c|c|c|}
\hline \multicolumn{5}{|c|}{ VARIABLE DEPENDIENTE: $\Delta$ PATENTES $_{t}$} \\
\hline & Coeficiente & DESV. TíPICA & Estadistico T & VALOR P \\
\hline Constante & 1763.26 & 1553.99 & 0.135 & 0.2596 \\
\hline PIBT-1 & -128.592 & 143.225 & -0.8978 & 0.3717 \\
\hline РІВT-2 119.651 & 128.806 & 0.9289 & 0.3555 & \\
\hline РIBT-3 & 194.033 & 115.458 & 1.681 & $0.0964^{*}$ \\
\hline РIBT-4 & -122.545 & 118.964 & -1.030 & 0.3058 \\
\hline PIBT-5 & 87.7066 & 136.458 & 0.6427 & 0.5221 \\
\hline PATENTES T-1 & -0.350304 & 0.118852 & -2.947 & $0.0041 * * *$ \\
\hline PATENTES T-2 & -0.416912 & 0.125717 & -3.316 & $0.0013 * * *$ \\
\hline PATENTES T-3 & -0.395848 & 0.126189 & -3.137 & $0.0023 * * *$ \\
\hline PATENTES T-4 & -0.0622343 & 0.124291 & -0.5007 & 0.6178 \\
\hline PATENTES T- 5 & 0.00242381 & 0.111728 & 0.02169 & 0.9827 \\
\hline 1995Q2 & -31.1582 & 27.9188 & -1.116 & 0.2674 \\
\hline ECT & -111.268 & 98.2077 & -1.133 & 0.2603 \\
\hline
\end{tabular}

$L^{* * *, * *} y *$, indican, respectivamente, 1,5 y 10 por ciento de significancia. 
Gráfica 10. Respuestas a impulsos dentro de una banda del 90 por ciento de confianza

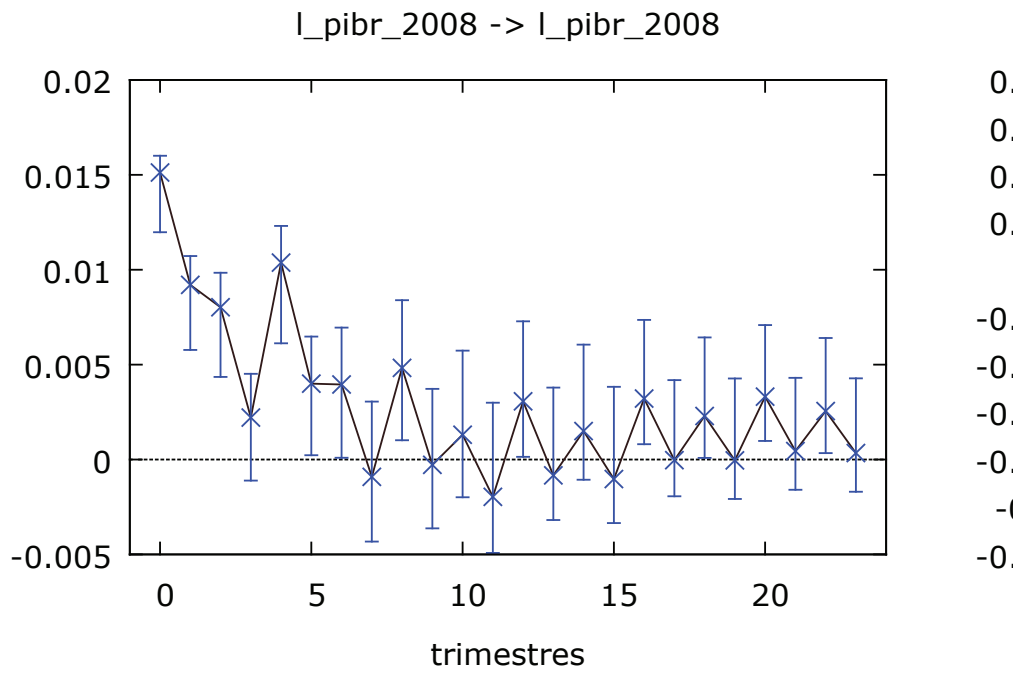

patentes -> I_pibr_2008

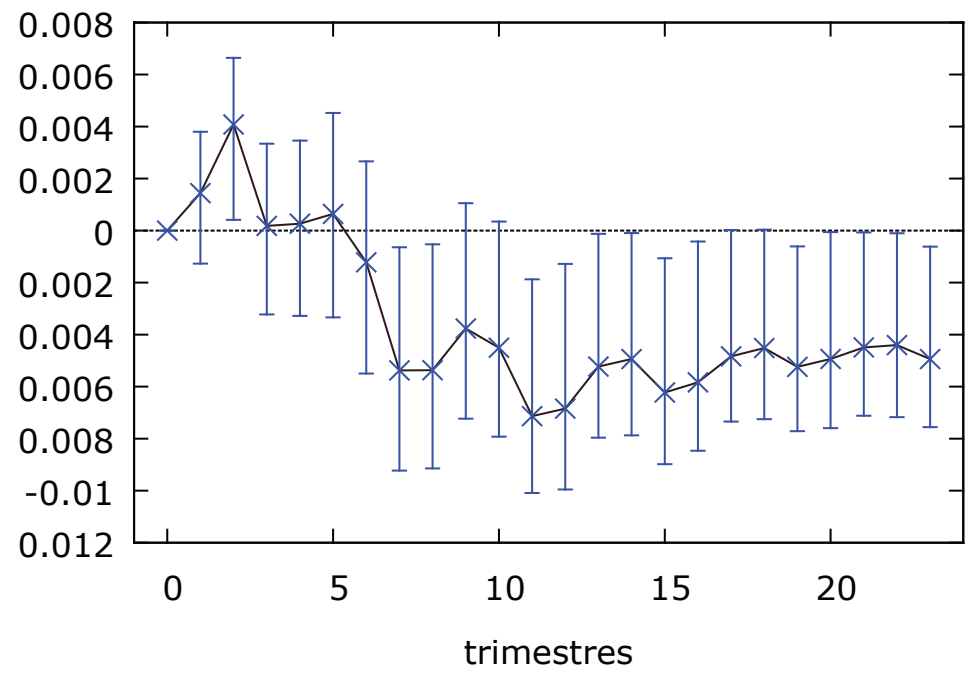


208 EConomía Teoría y PRÁctica • Nueva Época, Número especial, vol. 4, agosto 2018

Gráfica 10. Continuación
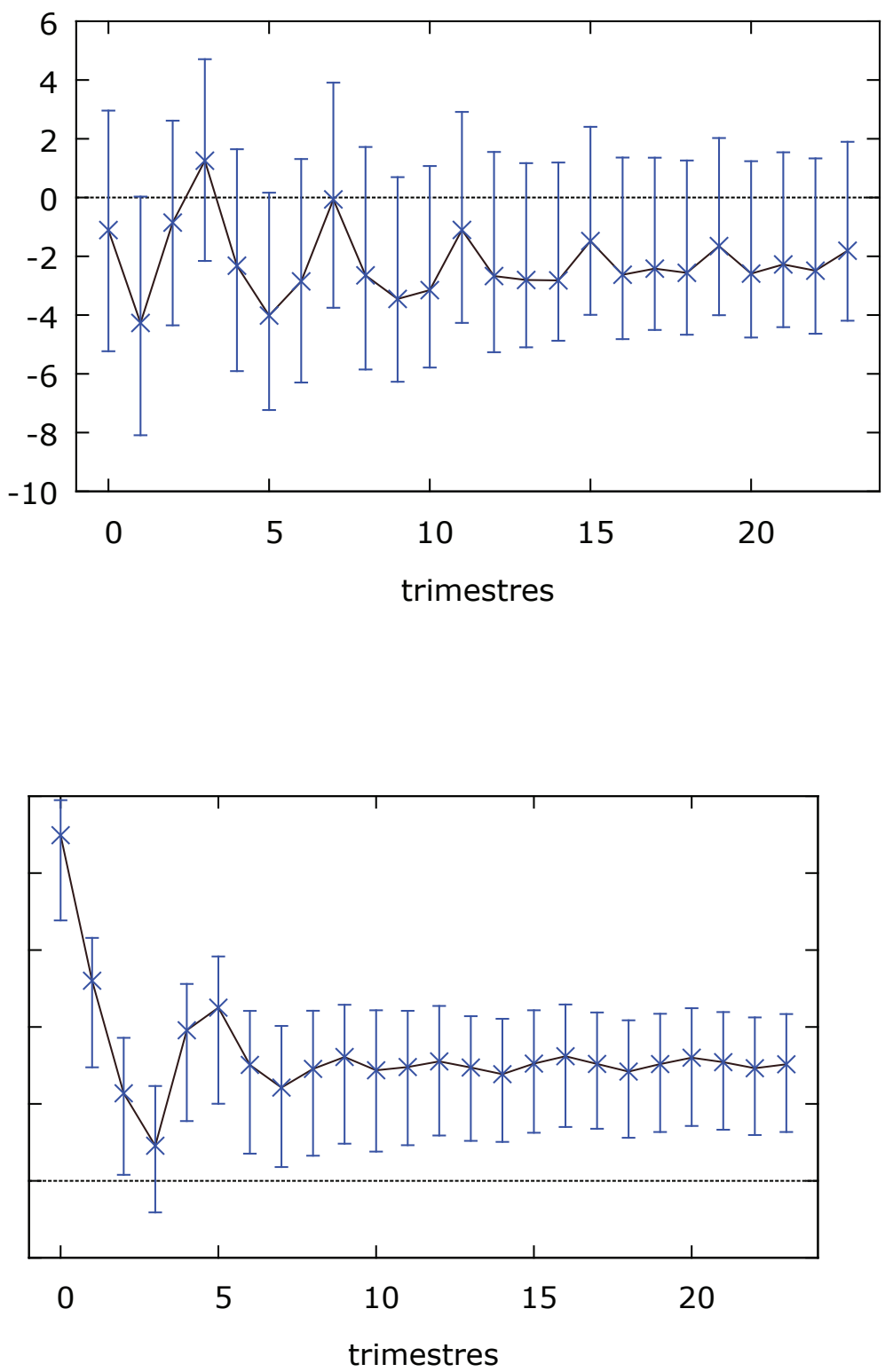
El efecto de un impulso (choque) en el PIB puede desvanecerse dentro de un periodo de ocho trimestres; pero tal efecto, en las patentes concedidas, aunque podría ser negativo, también fluctuaría en torno a cero prácticamente después de un trimestre (véase gráfica 10). Respecto a la ocurrencia de un impulso (choque) en el número de patentes, se aprecian efectos negativos, relativamente persistentes, al mantenerse con valores distintos de cero a partir del séptimo semestre posterior sin que desaparezca su efecto. Dichos impulsos también muestran efectos persistentes y distintos de cero sobre el número de patentes. Más patentes pueden generar más patentes.

\section{CONCLUSiones}

Esta investigación nos ha permitido constatar la excesiva dependencia tecnológica de México frente a sus dos socios del TLCAN, al relacionar las patentes de residentes/ patentes de no residentes concedidas en el IMPI. Las grandes beneficiarias de los DPI en el marco del ADPIC y el TLCAN han sido las empresas transnacionales, especialmente las estadounidenses, con cuantiosas regalías y pagos. Las firmas extranjeras, que han realizado inversión extranjera directa o exportan tecnología a México, cuentan con el dominio de las patentes solicitadas y concedidas en el Instituto Mexicano de la Propiedad Intelectual (IMPI). En cambio, las empresas locales han sido marginales para patentar novedades endógenas, asociado al bajo esfuerzo destinado a la ID y la ausencia de políticas institucionales e industriales orientadas a incrementar las capacidades tecnológicas y de innovación. En consecuencia, se ha reforzado la dependencia tecnológica con el exterior, especialmente hacia los Estados Unidos.

Se espera que el creciente número de patentes de titulares mexicanos residentes pueda tener un impacto en el crecimiento económico, pero, contrariamente el incremento del PIB podría no afectar positivamente el aumento de patentes, debido a un gasto de ID/PIB aún bajo y una política industrial ausente.

Consideramos de especial relevancia identificar los efectos que se desprenden de la instauración de un sistema de propiedad intelectual totalmente vinculado al TLCAN en términos de difusión tecnológica y de innovación endógena.

\section{REFERENCIAS}

Aghion, Phillipe y Howitt, Pierre (1998), Endogenous Growth Theory, Cambridge y London, The miт Press.

Antonelli, Cristiano (2017), Endogenous Innovation. The economics of an Emergent System Property, Cheltenham, uK, Massachusetts, us, Edgar Elgar. 
Aoki, Reiko y Prusa, Thomas J. (1993), "International standards for intellectual property protection and R\&D incentives", Journal of International Economics, 35, pp. 251-273.

Arrow, Kenneth J. (1962), "The economic implications of learning by doing", Review of Economic Studies, vol. 29, núm. 3, junio, pp. 155-173.

Atun, Rifat; Harvey, Ian y Wild, Joff (2007), "Innovation, patents and economic growth", International Journal of Innovation Management, vol. 11, núm. 2, junio, pp. 279-297. DOI. 10.1142/S1363919607001758.

Barro, Robert J. (1990), “Government Spending in a Simple Model of Endogenous Growth”, Journal of Political Economy, vol. 98, núm. 5, II, pp. 103-125.

Baumol (1993); Baumol, W. (1986), "Productivity Growth, Convergence and Welfare: What the Long-Run Data Show", American Economic Review, vol. 76, núm. 5, diciembre, pp. 1072-1085.

Braga, Primo, Carlos A. (1996), “Trade-Related Intellectual Property Issues: The Uruguay Round Agreement and its Economic Implications", The Uruguay Round and the Developing Countries, Martin, Will y Winters, L. Alan (eds.), pp. 341-344.

Coe, D. y Helpman, E. (1995), “International R\&D Spillovers", European Economic Review, núm. 39, pp. 859-887.

Constatinos, Alexiou; Nellis, Joseph y Papageogiadis, Nikolaos (2016), “The effect of patent enforcement strength and FDI on economic growth", $M u l-$ tinational Bussiness Review, vol. 24, núm. 4, pp. 334-353. DOI.10.1108/ MBR-07-2016-0024.

Correa, Carlos M. y Musungu, Sisule F. (2002), "The wIPo Patent Agenda: The Risks for Developing Countries 26", S. Ctr., Trade-Related Agenda, Development and Equity (T.R.A.D.E.) Working Papers, Paper núm. 12, noviembre.

Correa, Carlos M. (2009), "The Push for Stronger Enforcement Rules: Implications for Developing Countries", Centre for Interdisciplinary Studies on Industrial Property and Economics, University of Buenos Aires, International Centre for Trade and Sustainable Development (ICTSD), 2009, The Global Debate on the Enforcement of Intellectual Property Rights and Developing Countries, Programme on Intellectual Property Rights and Sustainable Development, Ginebra, febrero. https://www.files.ethz.ch/ isn/102256/2009-03_fink-correa-web.pdf

Dosi, G. (1988), "Sources, procedures and microeconomic effects of innovation", Journal of Economic Literature, vol. 26. 
Erstling, Jay y Strom, Ryan E. (2010), “Korea's Patent Policy and Its Impact on Economic Development: A Model for Emerging Countries?", Mitchell Hamline School of Law, 11 San Diego International Law Journal, 11 San Diego Int'l L. J., primavera, pp. 441-480.

Fink, Carsten y Primo Braga, Carlos A. (2005), "How Stronger Protection of Intellectual Property Rights Affects International Trade Flows", en Cartens, Fink y Keith, E. Maskus, Intellectual Property and Development. Lessons from Recent Economic Research, Washington D. C., World Bank y Oxford University Press, pp. 19-40.

Fink, Carsten (2009), Enforcing Intellectual Property Rights: an Economic Perspective, Group d'Economie Mondiale, Sciences Po Paris, Issue Paper, núm. 22, en International Centre for Trade and Sustainable Development (ICTSD) 2009, The Global Debate on the Enforcement of Intellectual Property Rights and Developing Countries, Programme on Intellectual Property Rights and Sustainable Development, Ginebra, febrero. https:// www.files.ethz.ch/isn/102256/2009-03_fink-correa-web.pdf

Gana, Ruth L. (1996), "Prospects for Developing Countries Under the TRIPS Agreement”, 29 VAND. J. TRANSNAT'L L. 735.

García, Frank J. (1993), "Protection of Intellectual Property Rights in the North American Free Trade Agreement: A Successful Case of Regional Trade Regulation", American University International Law Review, vol. 8 (4), pp. 817-837.

Gould, David, M. y Gruben, William C. (1996), "The role of intelectual property rights in economic growth”, vol. 48, núm. 2, marzo, pp. 323-350, DOI. ORG/10.1016/0304-3878(95)00039-9.

Grilliches, Zvi (1982), R\&D, Patents and Productivity, National Bureau of Economic Research, Chicago y Londres, Universiy of Chicago Press. (1990), "Patent Statistics as Economic Indicators: A Survey", Journal of Economic Literature, 28, diciembre, pp. 1661-1707.

Grossman, G. M. y Helpman, E. (1992), Innovation and Growth, The MIT Press, Cambridge, Massachusetts, Londres.

Guzmán, Alenka y Zúñiga, María Pluvia (2004), "Patentes en la industria farmacéutica de México: los efectos en la I\&D y la innovación”, Comercio Exterior, vol. 54, núm. 12, diciembre, pp. 1104-1121.

Guzmán, Alenka y Viniegra, Gustavo (coords) (2005), Industria farmacéutica y propiedad intelectual: los países en desarrollo, Editorial Miguel Ángel Porrúa-UAm, México, 418 pp. 
Hall, Bronwyn H. y Harhoff, Dietmar (2012), "Recent Research on the Economics of Patents", Annual Review of Economics, Annual Reviews, vol. 4, núm. 1, julio, pp. 541-565.

Hu, Albert G. Z. y Png, I. P. L. (2013), "Patent rights and economic growth: Evidence from cross-country panels of manufacturing industries", Oxford Economic Papers, vol. 65, núm 3, julio, pp. 675-698. DOI.10.1093/OEP/ GPT011.

Hussain, Imtiaz y Dominguez, Roberto (2015), "NAFTA and Intellectual Property Rights: Regionally Strapped?", North American Regionalism and Global Spread, pp 73-93.

Imam, Ali (2005), "How patent protection helps Developing Countries", Aipla Quarterly Journal, vol 33, (4), otoño, pp. 377-395.

International Centre for Trade and Sustainable Development (ICTSD) (2009), The Global Debate on the Enforcement of Intellectual Property Rights and Developing Countries, Programme on Intellectual Property Rights and Sustainable Development, Ginebra, febrero. https://www.files.ethz.ch/ isn/102256/2009-03_fink-correa-web.pdfLederman, Daniel; Maloney, William F. y Servén, Luis (2003), Lessons from NAFTA for Latin American and Caribbean (LAC) Countries: A Summary of Research Findings, World Bank. http://siteresources.worldbank.org/DEC/Resources/BookNAFTAWorld Bank.pdf

Lucas, Robert E. (1988), "On the Mechanics of Economic Development", Journal of Monetary Economics, vol. 22, núm. 1, pp. 3-42. https://DOI. ORG/10.1016/0304-3932(88)90168-7

Malerba, Franco; Nelson, Richard; Orsenigo, Luigi y Winter, Sidney G. (1999), "History-friendly models of industry evolution: The computer industry", Industrial and Corporate Change, vol. 8, núm. 1, pp. 3-40.

Maradana, Rana, P.; Pradhan, Rudra P.; Dash, Saurav; Gaurav, Kunal; Jayakumar, Manju y Chatterjee, Debaleena, (2017), "Does innovation promote economic growth? Evidence from European countries", Journal of Innovation and Entrepreneurship, vol. 6, núm.1, diciembre, pp. 1-26. DOI 10.1186/s13731-016-0061-9.

Marshall, Alfred (1920), Principles of economics, Londres, MacMillan. 8a.ed.

Nelson, Richard R. y Winter, Sidney (1993), National Systems of Innovation. A Comparative Study, Oxford, Oxford University Press.

Park, W. y Ginarte, J. C. (1997), "Intellectual Property Rights and Economic Growth”, Contemporany Economic Policy, vol. 15, núm. 3, pp. 51-61. 
Park, E. (2008), “International Patent Protection: 1960-2005”, Research Policy, vol 37, núm. 4, pp. 761-766.

Park, Walter, G. (2011), "Technology Trade and NAFTA", Economics Research, vol. 25, pp. 1-39. http://fs2.american.edu/wgp/www/Tech\%20Trade $\% 20$ NAFTA.pdf

Primo Braga, Carlos A. (1996), “Trade-Related Intellectual Property Issues: The Uruguay Round Agreement and its Economic Implications", The Uruguay Round and the Developing Countries, Martin, Will y Winters, L. Alan (eds.), pp. 341-344.

Romer P. M. (1990), "Endogenous Technical Change", Journal of Political Economy, vol. 98, núm. 5, pp. S71-S102.

Scherer, F. M. (1999), New Perspectives on Economic Growth and Technological Innovation, Washington, D. C., Brooking Institution Press.

Shadlen, Ken; Guzmán, Alenka; Guennif, Samira y Narayanan, Lalitha (coords.) (2011), Intellectual property, Pharmaceuticals and Public Health. Access to drugs in developing countries, Cheltenham, U.K. y Northampton, US, Edgar Elgar, 338 pp.

Schumpeter, Joseph A. (1912), Theory of Economic Development, Harvard University Press, (ed. 1961).

(1947), "The creative response in economic history", Journal of Economic History, vol. 7, núm. 2, pp. 149-159.

Solow, Robert (1957), "Technical Change and the Aggregate Production Function", Review of Economics and Statistics, vol. 39, núm. 3, pp. 312-320.

Taylor, M. S. (1994), “Trips, Trade and Growth”, International Economic Review, vol. 35 núm. 2, pp. 361-385.

Thompson, Mark A. y Rushing, Francis W. (1996), “An Empirical Analysis of the Impact of Patent Protection on Economic Growth", Journal of Economic Development, vol. 21, núm. 2, pp. 61-79. (1999), "An empirical Analysis of the Impact of Patent Protection on Economic Growth: An Extension", Journal of Economic Development, vol. 24, núm. 1, junio, pp. 67-76. 
